\title{
Understanding the Relationship between Dental Fear, Behavior Management Problems, and Caregiver-Child Interactions during Young Child Dental Appointments
}

Christopher Kyle Owen

West Virginia University, cko0005@mix.wvu.edu

Follow this and additional works at: https://researchrepository.wvu.edu/etd

Part of the Child Psychology Commons, Clinical Psychology Commons, and the Health Psychology Commons

\section{Recommended Citation}

Owen, Christopher Kyle, "Understanding the Relationship between Dental Fear, Behavior Management Problems, and Caregiver-Child Interactions during Young Child Dental Appointments" (2020). Graduate Theses, Dissertations, and Problem Reports. 7644.

https://researchrepository.wvu.edu/etd/7644

This Thesis is protected by copyright and/or related rights. It has been brought to you by the The Research Repository @ WVU with permission from the rights-holder(s). You are free to use this Thesis in any way that is permitted by the copyright and related rights legislation that applies to your use. For other uses you must obtain permission from the rights-holder(s) directly, unless additional rights are indicated by a Creative Commons license in the record and/ or on the work itself. This Thesis has been accepted for inclusion in WVU Graduate Theses, Dissertations, and Problem Reports collection by an authorized administrator of The Research Repository @ WVU. For more information, please contact researchrepository@mail.wvu.edu. 
Understanding the Relationship between Dental Fear, Behavior Management Problems, and Caregiver-Child Interactions during Young Child Dental Appointments

Christopher K. Owen, B.S.

Thesis defense submitted

to the Eberly College of Arts and Sciences

at West Virginia University

in partial fulfillment of the requirements for the degree of

Master of Science in

Psychology

Cheryl B. McNeil, Ph.D., Chair

Daniel W. McNeil, Ph.D.

Christa L. Lilly, Ph.D.

Department of Psychology

Morgantown, West Virginia

2019

Keywords: Behavior management, parent-child interactions, child dental fear, caregiver dental fear

Copyright 2020 Christopher K. Owen 


\section{Abstract \\ Understanding the Relationship between Dental Fear, Behavior Management Problems, and Caregiver-Child Interactions during Young Child Dental Appointments}

\section{Christopher K. Owen}

Positive oral health practices should begin early in life (AAPD; 2013; 2014; 2015); however, dental care-related fear and anxiety and behavior management problems are prevalent among young children in oral health (Klingberg \& Broberg, 2007). The study explored caregiver and child dental care-related fear and anxiety, child behavior, and caregiver-child interactions during early childhood dental appointments. Caregiver-child dyad participants $(\mathrm{N}=140)$ were collected from dental practices in West Virginia, Ohio, and Tennessee. Children $(n=139)$ in the sample were largely White (69.8\%) and male (54.0\%), with an average age of 3.05 years. Video-taped dental appointments for children under six years were used to code for verbal and behavioral interactions between the caregiver and child. Caregiver dental fear, caregiver-report of child dental fear, and provider-report of child behavior during the dental appointment were also used in subsequent analyses. Analyses indicated that child dental fear had a statistically significant negative association with child behavior during dental appointments $(r=-.39, p<.001)$. Children with high dental fear were significantly more likely $(\mathrm{OR}=3.65)$ of having negative behavior during dental appointments. Caregiver dental fear was not significantly $\left(r_{s}=.10, p=\right.$ $.25)$ associated with child behavior. Children complied significantly more with direct commands $(M d n=.25)$ compared to indirect commands $(M d n=.00)$ from caregivers $(T=-3.91, p<.001)$. Providers and caregivers have opportunities to improve early dental experiences for young children. Providers may benefit from screening for child dental fear to improve patient care. Caregivers may consider using direct commands to elicit child compliance, as well as increase their overall usage of labeled praise to make appointments more positive overall. 


\section{Acknowledgements}

My deepest gratitude goes out to my advisor and committee. You all have gone above and beyond mentoring me throughout this process, and I'm a better research because of it. I'd also like to recognize the extensive work from all of the undergraduates in the Parent Child Interaction Therapy (PCIT) and Anxiety, Psychophysiology, and Pain (APP) research laboratories. It's a privilege to have worked with you all on the larger grant supporting this research study. Funding for this study was provided by the National Institute of Dental and Craniofacial Research (NIDCR/NIH, R21-DE026540). 


\section{Table of Contents}

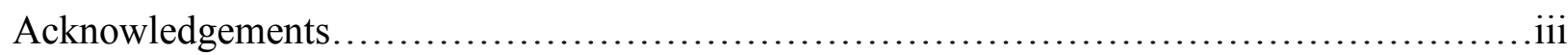

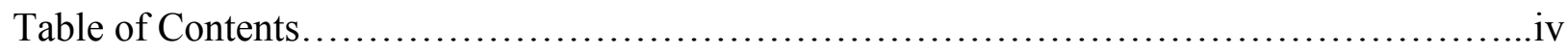

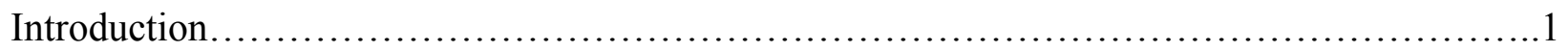

Child Dental Fear and Behavior................................................

Dental Fear................................................................

Dental Fear and Oral Health..............................................4

Relationship between Dental Fear in Parents and Children..........................5

Fear Acquisition...........................................................

Pathways........................................................6

Dental care-related fear pathways.....................................

Parent-Child Interaction Pathway.............................................

Dyadic Parent-Child Interaction Coding System........................... 9

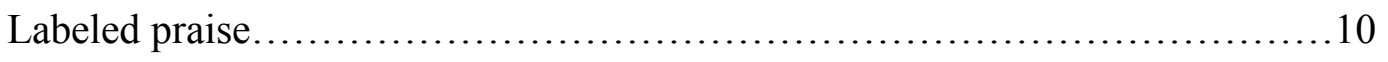

Commands.......................................................10

Direct commands...........................................11

Negative talk...................................................11

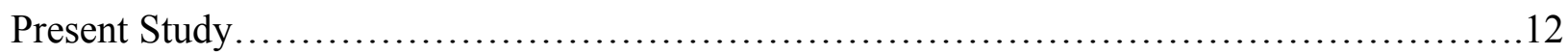

Hypotheses......................................................... 12

Child fear and behavior............................................. 12

Caregiver fear and child behavior..................................... 13

Caregiver-child interactions and child behavior........................... 14

Method.......................................................................... 14 


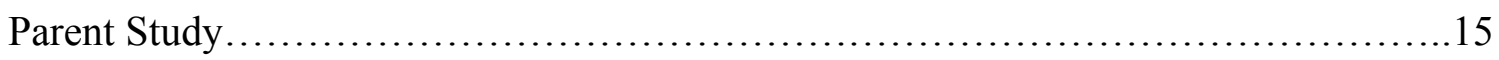

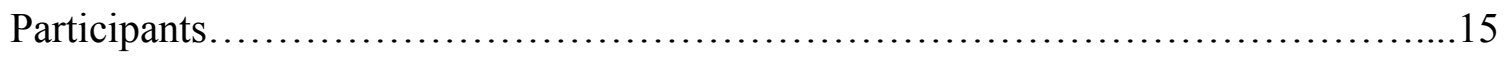

Dental professionals................................................... 15

Caregivers and children.................................................. 16

Procedures................................................................................

Practices................................................................ 16

Dental professionals.................................................... 16

Caregivers and children.............................................. 17

Video transcripts....................................................... 17

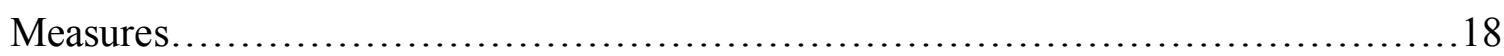

Child Behavior Checklist (CBCL) .....................................18

Demographic Information Forms.............................................19

Dental Fear Survey (DFS) .............................................19

Dental Subscale of the Children's Fear Survey (CFSS-DS)....................20

Dyadic Parent-Child Interaction Coding System, Fourth Edition (DPICS-IV)...20

Psychometrics................................................... 21

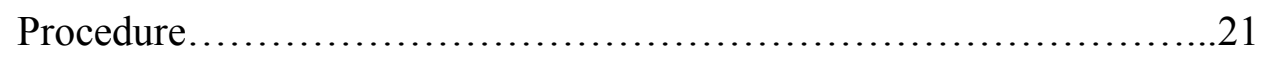

Inter-coder agreement..............................................23

Frankl Scale........................................................... 24

Subjective Units of Distress (SUDS) .....................................25

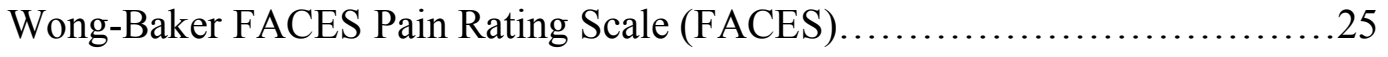

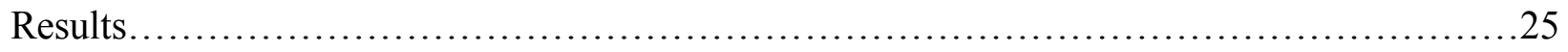

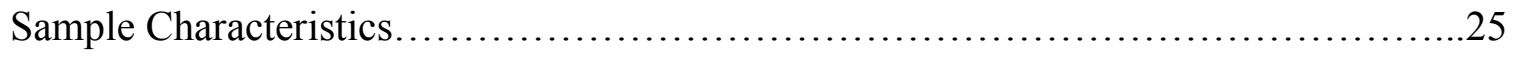


Missing and Preliminary Analyses...........................................27

Child Fear and Child Behavior....................................................

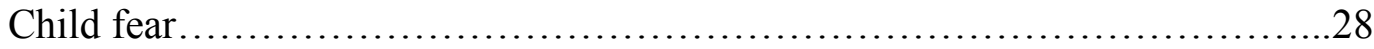

Frankl scale with four levels...........................................28

Frankl scale with two levels........................................... 30

Frankl scale with two levels on CFSS-DS cut-scores.........................30

CFSS-DS in positive and negative appointments.......................... 31

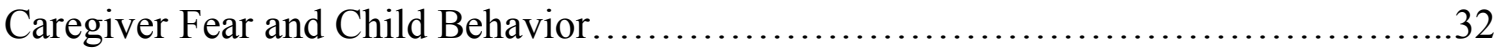

Caregiver fear..................................................... 32

Frankl scale with four levels........................................... 32

Frankl scale with two levels.............................................33

DFS in positive and negative appointments............................ 34

Caregiver-Child Interactions and Child Behavior................................. 35

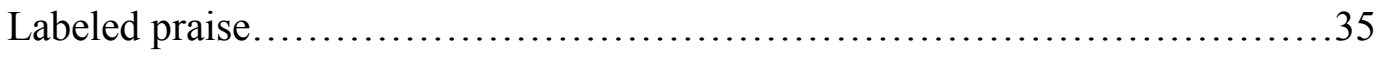

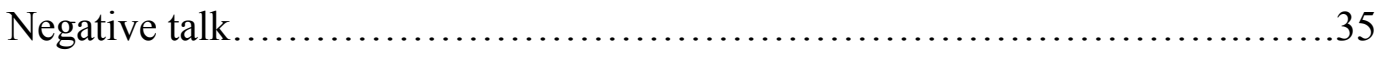

Child compliance to direct and indirect commands............................35

Exploratory Analyses....................................................

Caregiver-child interactions, dental fear, and child behavior..................36

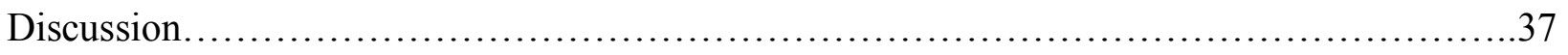

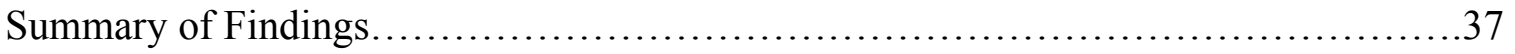

Child Fear and Child Behavior................................................. 38

Caregiver Fear and Child Behavior..........................................40

Caregiver-Child Interactions and Child Behavior...............................42 


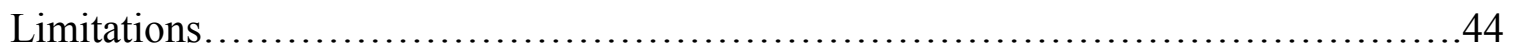

Future Directions...............................................................

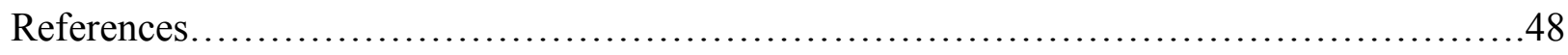

Table 1: Definitions and Examples of DPICS-IV Codes....................................58

Table 2: Caregiver Sample Characteristics..............................................60

Table 3: Child Sample Characteristics.................................................6 62

Table 4: Parameters from the Ordinal Regression of CFSS-DS Scores on Frankl Scores.........64

Table 5: Logistic Regression Analysis for CFSS-DS associated with Binary Frank1..............64

Table 6: Logistic Regression Analysis for Cut Scores on Binary Frankl Scores..................64

Table 7: Logistic Regression Analysis for DFS associated with Binary Frank1..................64

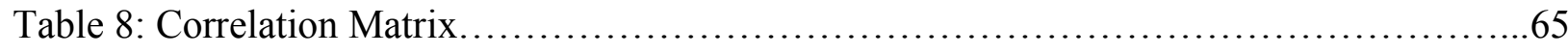

Table 9: Caregiver-Child DPICS-IV Sample Characteristics..............................67

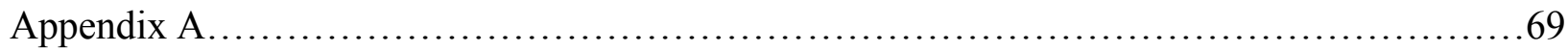

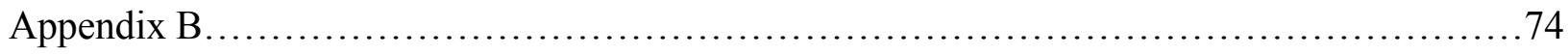

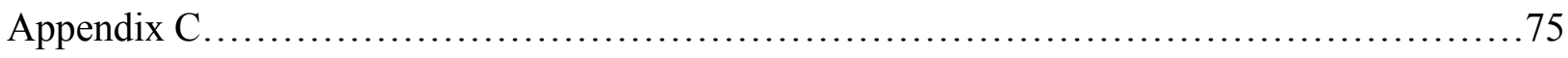


Understanding the Relationship between Dental Fear, Behavior Management Problems, and Caregiver-Child Interactions during Young Child Dental Appointments

The foundations for lifelong health behaviors are established early in childhood (Blane, 1999). According to the American Academy of Pediatric Dentistry (AAPD; 2015), preventative dental care early in life reduces incidence of dental disease, decreases treatment needs, and leads to fewer opportunities for negative experiences. The AAPD $(2011 ; 2013 ; 2014)$ recommends providers begin seeing patients for the first oral examination around 12 months of age to facilitate early detection and management of dental care.

Along with disease considerations, preventative care is important for reducing the risk of dental care-related fear and anxiety, a common concern in childhood oral health (Klingberg \& Broberg, 2007; Weinstein, 1990). According to McNeil and Randall (2014) dental care-related fear has been defined as a distress response to dental treatment stimuli. An additional concern with young child dental appointments is dental behavior management problems, which often occur in children with dental fear (Klingberg, Berggren, Carlsson, \& Noren, 1995). Dental behavior management problems have been defined as uncooperative and disruptive behaviors that negatively impact treatment, such as delaying or making treatment impossible (Klingberg, Löfqvist, Bjarnason, \& Norén, 1994). Research demonstrates that dental care-related fear and anxiety and dental behavior management problems are related, in that $61 \%$ of children with dental care-related fear and anxiety also displayed behavior management problems (Klingberg et al., 1995).

Research across several fields has suggested that dental care-related fear and anxiety in addition to child behavior problems negatively impacts dental care and systemic health throughout life (Milgrom, Mancl, King, \& Weinstein, 1995; Schuller, Willumsen, \& Holst, 
2003). For this reason, dental care-related fear and anxiety are prevalent global public health concerns (McNeil \& Randall, 2014). Given the suggested importance of dental-care related fear and anxiety on overall health, further research is necessary to understand its role in young children's behavior during dental appointments and in the context of caregiver-child interactions.

The study examined caregiver and child dental care-related fear and anxiety, child behavior, and caregiver-child interactions during early childhood dental appointments. The study aimed to investigate: (a) the relationship between child dental fear and child behavior, (b) the relationship between caregiver dental care-related fear and anxiety and child behavior, (c) associations between caregiver-child interactions and child behavior, and (d) ways that caregiver-child interactions may influence the relationship between child dental care-related fear and anxiety, and child behavior.

\section{Child Dental Fear and Behavior}

Dental behavior management problems are defined as uncooperative and disruptive behaviors that negatively impact treatment, such as delaying or making treatment impossible (Klingberg et al., 1994), and often provided by dental providers via behavior observations. According to a review, both dental fear and dental behavior management problems affect about $9 \%$ of children and adolescents, and the origins of dental fear and dental behavior management problems are likely to be multifactorial (Klingberg \& Broberg, 2007). Thus, both dental fear and behavior management problems in children are relatively common in dentistry. Factors other than dental fear may contribute to the development of dental behavior management problems; for example, not all children with dental fear subsequently had behavior management problems (Klingberg et al., 1995). That is, only $61 \%$ of children with dental fear subsequently have behavior management problems (Klingberg et al., 1995). Children may present with: (a) dental 
behavior management problems without dental fear and anxiety, (b) dental fear and anxiety without dental behavior management problems, and (c) dental behavior management problems with dental fear and anxiety (Klingberg, Raadal, \& Arnrup, 2016).

The reciprocal relationship between dental fear and behavior management problems negatively impacts oral health care in children. For instance, Klingberg et al. (1994) found that children with behavior management problems had more missing appointments and dental caries than children without behavior management problems. Particularly important, the frequency of behavior management problems is more common in younger children than older children (Klingberg et al., 1994). Given the relationship between dental fear and behavior management problems, research has prioritized the investigation of specific behavioral techniques that reduce fear and increase child compliance to commands during dental appointments.

\section{Dental Fear}

Researchers have demonstrated that fear and anxiety are two distinct, overlapping phenomena (McNeil et al., 1993; Poulton et al., 2001; Thomson et al., 2009). Compared to fear, anxiety constitutes an emotional state with more cognitive symptoms (e.g., negative thoughts and worries), less visceral activation, and cues that are more temporally and spatially removed from the situation (Craske, 2003; McNeil et al., 2012). Thus, dental care-related anxiety is a more cognitively involved emotional response to dental treatment stimuli than dental fear. Although similar to anxiety, fear constitutes an emotional state involving more mobilization for physical action and typically contains cues that are immediately present (McNeil et al., 2012). Thus, dental care-related fear is a distress response to dental treatment stimuli. According to McNeil and Randall (2014) this often includes physiological responsivity as well as reports of apprehension and avoidance. Dental care-related fear and anxiety are distinct yet related states, 
and more accurately conceptualized across a continuum rather than a dichotomous phenomenon (McNeil \& Randall, 2014). Conceptually, according to Felicione, Blank, Wright, and McNeil (2018), researchers must consider important definitional distinctions and similarities among these states as well as acknowledge that often more than one state is simultaneously involved. For the purposes of this paper, the term dental fear will subsequently be used as shorthand when referring to dental care-related fear and anxiety.

\section{Dental Fear and Oral Health}

Approximately 6-20\% of children and adolescents present with dental fear (Klingberg \& Broberg, 2007). Weinstein (1990) presented a cyclical model of pain, fear and avoidance, where in severe dental pathology is treated with invasive — often painful—procedures resulting in increased fear and avoidant behavior. Furthermore, a study by Milgrom et al. (1995) provided partial validation of this cyclical model in caregivers and children. An unfortunate outcome of this avoidance cycle is that adults and children with dental fear have been shown to have poorer oral health and oral-health-related quality of life than those without dental fear (Armfield, 2010; Armfield \& Heaton, 2013; Cohen, Fiske, \& Newton, 2000; Hamzah, Gao, Yiu, McGrath, \& King, 2014; Klingberg et al., 1995; Luoto et al., 2009; Mehrstedt et al., 2004; Ng \& Leung, 2008). Furthermore, fearful adults, who may only seek dental care on an emergent basis, often

reinforce children's dental fear by transmitting attitudes that dental visits are aversive and painful (Armfield et al., 2007). Because dental fear in adults and children negatively impacts health in many ways the present study aims to examine the relationships between caregiver dental fear, child dental fear, and caregiver-child interactions.

\section{Relationship between Dental Fear in Parents and Children}


Research has shown that fearfulness in parents relates to child fearfulness. For example, general fearfulness of children was demonstrated to be related to general fearfulness of the mother (Muris, Steerneman, Merckelbach, \& Meesters, 1996). Additionally, researchers found a linear association between children's fearfulness and mothers' rating of expressing fears to their children; in that, children of mothers who never expressed their fear had the lowest fear scores, while children of mothers who expressed their fears had the highest fear scores. Research has also demonstrated that dental fear in parents relates to child dental fear. According to a recent meta-analysis, $79 \%$ of reviewed studies identified a significant relationship between parental and child dental fear (Themessl-Huber, Freeman, Humphris, MacGillivray, \& Terzi, 2010). Research has found that maternal dental fear impacts the development of dental fear in children. For instance, a study examining the relationship among caregiver dental fear, child dental fear, and possible clinical effects found age, general fears, and maternal dental fear influenced child dental fear (Klingberg et al., 1995). With respect to age, a review by Themessl-Huber et al. (2010) found that the dental fear of children under the age of eight is significantly related to parent dental fear; however, the relationship between parental and child dental fear for children over eight was less clear. There was additional support, via meta-analytical results converging with detailed study-by-study assessment, with the finding that children of younger age have a significant positive association of dental fear with their parent $(r=0.296, p=0.018$; ThemesslHuber et al., 2010). Given this information, further research is necessary to: (a) study the link between parental and child dental fear, and (b) conduct more extensive studies exploring dental fear acquisition in children.

\section{Fear Acquisition}


Pathways. Rachman (1977) proposed that fear acquisition may occur through the following three pathways: direct conditioning, vicarious experiences, and instruction/information. In support of the direct conditioning pathway, Lautch (1971) found that all dental phobic patients reported having had a traumatic dental experience on at least one occasion in childhood. While direct conditioning is grounded in classical conditioning, the two other major indirect pathways to fear acquisition include vicarious experiences and instruction/information (Rachman, 1977). Vicarious learning experience is grounded in the processes of observational learning and modelling, and with empirical support from successful vicarious fear-reduction demonstrations (Bandura, 1969, 1971). According to Rachman (1977), the most overlooked pathway is the transmission of information, which occurs in a constant fashion for young children from caregivers and peers.

Ollendick and King (1991) suggested that fear acquisition occurs synergistically through three independent pathways: direct conditioning, vicarious experiences, and modeling. In this study, 1092 children and adolescents completed a questionnaire that included questions about common pathways of acquisition and onset of their fears. Results showed that fearful children attributed the onset of their fears to vicarious (56\%) and instructional (89\%) more often than direct condition (36\%) events (Ollendick \& King, 1991). Furthermore, this study found, depending on the specific fear, that it was necessary for (1) both indirect sources of fear to be present (i.e., vicarious and instructional) or (2) both indirect sources to be combined with direct conditioning experiences before high levels of fear were reported (Ollendick \& King, 1991). Thus, the three pathways may be considered more interactive rather than independent. An integrated fear pathway would help in identifying ways in which young children acquire dental fear, which may facilitate the development of interventions aimed at reducing dental fear. 
Dental care-related fear pathways. Because dental fear impacts lifelong oral health behavior and quality of life, an understanding of the acquisition pathways of dental care-related fear and anxiety could inform fear-reduction interventions to enhance patient management and care. Generally, the dental care-related fear acquisition literature has focused on direct conditioning. Few studies have examined the indirect conditioning of dental care-related fear pathways (Doerr et al., 1998), and indirect conditioning of dental fear in young children (Melamed \& Williamson, 1991). Furthermore, a recent review of fear and anxiety pathways in dentistry calls for future research to address the lack of literature examining the acquisition and origin of dental fear in children and adolescents (Carter, Carter, Boschen, AlShwaimi, \& George, 2014). With this knowledge, changes to current clinical practices may be considered, advancing oral health research toward more effective dental treatment.

While research has demonstrated direct conditioning facilitates fear acquisition through negative experiences with dental care, little is known about how fear is acquired in the absence of previous negative dental experiences. One study examined the Rachman's (1977) pathways to fear in a sample of low income American children ranging in age from five to 11 years (Milgrom et al., 1995). In this study, mother-child dyads were recruited to complete questionnaires and interviews using proxy measures to capture direct and modeled effects on the child's fear of the dentist; where in, child dental fear was measured using an adapted dental subscale of the Children's Fear Survey Scheduled (Melamed \& Lumley, 1988; Milgrom et al., 1995). For direct conditioning, researchers used a broad set of measures to represent direct experience with dental treatment (e.g., child's last dental visit and actual oral health status of child). The strongest direct conditioning variable association was oral health status; in that, children with emerging or overt caries were two times more likely to be fearful of the dentist than children with possible or no 
caries. For indirect conditioning, researchers used a set of mother self-reported measures to represent modeling effects (e.g., mother's fear of the dentist and assessment of mother's oral health). The strongest modeling variable association was mother dental fear; in that, children of mothers with moderate to high dental fear were twice as likely to be afraid of the dentist as children of mothers with low dental fear. In summary, the findings indicated that both direct conditioning and parent modeling serve as significant and independent predictors of dental fear levels in children after controlling for gender, age, and sociodemographic and attitudinal factors. Thus, it appears that parental modeling is an important pathway to consider when investigating the acquisition of dental fear in children.

While research supports that both direct and indirect pathways may influence dental fear acquisition in children, other research has investigated additional causes for dental fear in children. In their review of 32 articles, Klingberg and Broberg (2007) evaluated the relationship between dental fear and anxiety and dental behavior management problems with age, sex, general anxiety, temperament, and general behavioral problems. Results indicated three noteworthy relationships to dental fear in children: (a) previous negative experiences with dental care, (b) genetic predisposition to reactivity, and (c) anger and oppositional tendencies toward a variant of frustrating external demands. According to Klingberg and Broberg (2007), children prone to react with fear and anxiety expect to show a relationship between behavior problems and internalizing disorders, and children with oppositional tendencies expect to show a relationship between behavior problems and externalizing disorders. Previous negative experiences with dental care connect to a direct conditioning pathway, while the other two causes for dental fear in children may be acquired more indirectly. Given the shortcomings of 
relying only on a direct conditioning pathway, there is a need to explore new and integrated pathways.

\section{Parent-Child Interaction Pathway}

Although previous literature demonstrated a relationship between parent and child dental fear (Milgrom et al., 1995; Themessl-Huber et al., 2010), research has not explored whether active parent-child interactions are a mechanism of transmitting dental fear from parent to child during dental appointments. The parent-child interaction pathway may constitute a pathway that integrates both direct conditioning and indirect conditioning. For example, through classical conditioning, a parent may form or strengthen associations between dental treatment stimuli and aversive experiences during dental appointments (e.g., lack of control and pain). Through operant conditioning, a parent may promote dental fear through negative or positive reinforcement. Milgrom et al. (1995) demonstrated that children acquired dental fear vicariously through parental modeling. Finally, parents may also transmit dental fear through information giving (e.g., "Getting your teeth cleaned really hurts!"). In sum, parent-child interactions may represent an integrative pathway to explore potential mechanisms of dental fear transmission from parent to child; furthermore, it would also allow for an investigation of dental behavior management problems and child compliance.

Dyadic Parent-Child Interaction Coding System. The proposed study will use the Dyadic Parent-Child Interaction Coding System - Fourth Edition (DPICS-IV; Eyberg, Nelson, Ginn, Bhuivan, \& Boggs, 2013; Robinson \& Eyberg, 1981) to identify relationships between existing DPICS categories, parent and child dental fear, and child behavior during dental appointments. The DPICS is a psychometrically strong measure of parental and child behavior that initially was developed to evaluate outcomes associated with Parent-Child Interaction 
Therapy, an evidence-based parent training program designed for preschoolers with behavior problems (Funderburk, \& Eyberg, 2011; Lieneman, Brabson, Highlander, Wallace, \& McNeil, 2017; McNeil \& Hebmree-Kigin, 2010). The DPICS is comprised of parental verbalization codes (e.g., labeled praise, negative talk) that have a high impact on child behavior (Eyberg et al., 2013). These behavioral codes allow for an evaluation of parent-child interactions within the dental setting. These codes may be helpful in understanding the relationship between parent and child dental fear, as well as child behavior, during dental appointments.

Labeled praise. Research has demonstrated that praise increases compliance levels of children (Parpal \& Maccoby, 1985). In one study, researchers examined how types of parental social reinforcement affected a child's response using a game that involved dropping marbles into a green or red hole (Bernhardt \& Forehand, 1975). After obtaining a baseline, the experimenter cued the mother to reward the child for dropping the marble in the least-preferred hole during baseline. Mothers in the first group used unlabeled praise (e.g., nice job), and mothers in the second group used labeled praise (e.g., great job putting the marble in the red hole). Although both reward conditions increased the number of marbles dropped in the reward hole, labeled praise was associated with a significantly greater increase from baseline to postexperimental condition assessment compared to unlabeled praise (Bernhardt \& Forehand, 1975). That is, children performed an activity at a higher frequency after receiving labeled praise compared to unlabeled praise. Results indicate the importance of being specific when using verbal reinforcement (e.g., "good job of opening your mouth wide" instead of "that's good") when attempting to increase particular behaviors in young children.

Commands. Forehand and Scarboro (1975) investigated (a) how the number of parental commands effected child compliance and (b) the compliant act itself. In this study, mothers 
issued 12 commands to children, and each command was coded for the presence or absence of compliance. First, researchers demonstrated children complied significantly less with the final 6 commands compared to the first 6 commands. Thus, when parents increase the number of commands, child compliance is likely to decrease. Second, researchers found that children demonstrated significantly less compliance in the first 30 seconds following a command than after the first 30 seconds. This then would serve to indicate that failure to initiate compliance is a major factor in noncompliance, and attempts to increase compliance should focus on the initiation of compliance.

Direct commands. Further research has demonstrated that specific and direct parental commands increase children compliance (Forehand \& McMahon, 1981; Hembree-Kigin \& McNeil, 2013; Walker \& Walker, 1991). Roberts, McMahon, Forehand, and Humphreys (1978) conducted a study examining the interactive effects of parental instruction-giving on child compliance. Researchers trained mothers in the following three conditions: (1) command training, (2) command plus time-out training, and (3) placebo-control. Parents involved in the command training were taught to give commands that describe appropriate behavior, tell the child what to do (e.g., walk versus don't run), break down complex commands into smaller specific commands, and give a clear time limit (e.g., right now). Findings from this study showed both command training and command plus time-out training increased child compliance relative to a placebo-control condition. Thus, direct and specific commands increased child compliance more than indirect and nonspecific commands.

Negative talk. Parental negative talk includes smart talk (e.g., sarcasm) and critical statements (e.g., "I want you to stop acting like a brat") that express disapproval or include rude speech (Eyberg et al., 2013). Sachs-Ericsson, Verona, Joiner, and Preacher (2006) investigated 
the mediating role of current self-criticism on the relationship between previous parental verbal abuse (e.g., "you're stupid") and adult internalizing symptoms, and results indicated selfcriticism fully mediated the relationship between childhood verbal abuse from parents and internalizing (i.e., depression and anxiety) symptoms. Thus, verbal abuse influences the development of a self-critical style. Another study explored longitudinal links between harsh verbal discipline and future behavioral problems and depressive symptoms; results showed that parental verbal discipline increased conduct problems and depressive symptoms over time (Wang \& Kenny, 2014). Furthermore, a nationally representative sample of 3,346 parents with a child under 18 years of age showed that children who experienced frequent verbal aggression from parents exhibited higher rates of physical aggression, delinquency, and interpersonal problems than other children (Vissing, Straus, Gelles, \& Harrop, 1991). In sum, harsh parental verbal criticism is linked to problem behaviors and internalizing symptoms.

\section{Present Study}

The overarching goal of this study was to test hypotheses about psychosocial mechanisms of young child disruptive behavior during dental appointments. More specifically, the present study examined caregiver dental fear, child dental fear, and dyadic interactions between caregivers and young children during dental appointments. Understanding factors related to the transmission of dental fear in children may result in recommendations to improved clinical management, which may increase oral healthcare utilization and improve overall oral health.

\section{Hypotheses}

Child fear and behavior. The broader literature suggests that children with higher reports of dental fear are less likely to have positive behavior during a dental appointment 
(Klingberg \& Broberg, 2007). Therefore, it was expected that data from this sample of young children would reflect similar associations.

1. It was hypothesized that child dental fear would be positively correlated with negative child behavior during a dental appointment.

2. It was hypothesized that children with higher child dental fear would be significantly more likely to be classified as having poorer behavior during a dental appointment.

3. It was hypothesized that children with higher dental fear would have increased odds of having negative behavior during a dental appointments relative to children with lower dental fear.

4. It was hypothesized that children whose caregivers report them as having clinical dental fear (i.e., above the clinical cut off on a standardized measure) would have increased odds of having negative behavior during dental appointments relative to children whose caregivers report them as having normative levels of dental fear.

5. It was hypothesized that young children classified with negative behavior during dental appointments versus positive behavior during dental appointments were not equal across caregiver reports of child dental fear.

Caregiver fear and child behavior. The broader literature suggests that caregiver dental fear and child dental fear are related (Themessl-Huber et al., 2010). Additionally, previous research has demonstrated that child dental fear and dental behavior management problems are connected (Klingberg et al., 1995). Therefore, it was hypothesized that data from this sample of young children will reflect associations between caregiver dental fear and child behavior within a dental setting. 
1. It was hypothesized that caregiver dental fear would be negatively correlated with child behavior during a dental appointment.

2. It was hypothesized that children of caregivers with high dental fear would be significantly more likely to be classified as having poorer behavior during a dental appointment.

3. It was hypothesized that children of caregivers with high dental fear would have increased odds of having negative behavior during a dental appointments relative to caregivers with low dental fear.

4. It was hypothesized that young children classified with negative behavior during dental appointments versus positive behavior during dental appointments were not equal across caregiver self-report of dental fear.

Caregiver-child interactions and child behavior. No studies to date have related the DPICS and Frankl scale to show a direct correlation between parent-child interactions and child behavior during dental appointments. However, previous research from the parent training literature can be used to inform the hypotheses below.

1. It was anticipated that labeled praises would be positively correlated with positive behavior during young child dental appointments (Bernhardt \& Forehand, 1975).

2. It was anticipated that negative talk would be negatively correlated with positive behavior during young child dental appointments (Vissing et al., 1991; Wang \& Kenny, 2014).

3. It was anticipated that child compliance with direct commands would be higher than child compliance with indirect commands (Forehand \& McMahon, 1981; Hembree-Kigin \& McNeil, 1995; Roberts et al., 1978; Walker \& Walker, 1991).

\section{Method}




\section{Parent Study}

The study utilized collected data from providers and caregivers who participated in a larger study funded by the National Institute of Dental and Craniofacial Research (NIDCR; R21 DE026540; Provider-Patient-Caregiver Interactions in Pediatric Dentistry; PI's: McNeil \& McNeil). The parent study was a collaborative, multi-state project aimed at developing a triadic (i.e., dental professional, caregiver, child patient) coding system to provide an evidence-based method of understanding behavioral interactions in pediatric dental care. The parent study had the following specific objectives: (a) define, measure, and reliably code behaviors, interactional patterns, and environmental stimuli during pediatric dental care, (b) explore the relations between antecedents and specific behavioral outcomes during pediatric dental care, and (c) finalize an observational coding system with strong psychometric properties that assesses the antecedents that are most salient and relevant to specific behavior outcomes during pediatric dental care. The parent study aimed to build upon a previously validated adult-child interaction coding system for use with dental personnel, and to further analyze the relations between measured antecedents and behavioral outcomes.

\section{Participants}

Dental professionals, caregivers, and children participated in the proposed study. Participants were recruited from dentistry practices in West Virginia, Tennessee, and Ohio.

Dental professionals. The participants were chosen as a convenience sample, in that any participants who met the eligibility requirements were invited to participate. Professional participants eligible at the beginning of the study met the following inclusion criteria: (a) dental professionals (i.e., dentist, dental hygienist, and dental assistant), and (b) willing to participate in various study tasks (e.g., completing assessments, video-taping sessions). 
Caregivers and children. In the current investigation, 140 caregiver-child dyads participated in the study. The participants were chosen as a convenience sample, in that any participants who met the eligibility requirements were invited to participate. Participants eligible at the beginning of the study met the following inclusion criteria: (a) child under the age of six years old, (b) willing to participate in various study tasks (e.g., completing assessments, videotaping sessions). Because this study employed naturistic observation and little experimental control, there may be instances of sibling appointments. For example, two child participants may have a single caregiver. Furthermore, the nature of the sibling appointment may vary; in that, two siblings may have appointments back-to-back or in the room together during the entire time. To fully explore this rich naturalistic data set, analyses were run on all participants.

\section{Procedures}

Practices. Various dental practices were recruited via personal contacts of the investigators as well as flyers across 3 states: West Virginia, Tennessee, and Ohio. Dental practices were not affiliated with a university; that is, practices recruited included communitybased dental clinics, general dentistry practices, and pediatric dentistry practices. Study personnel travelled to recruited practices to consent staff, recruit participants, and collect data. Practices received the incentive that they would be given a presentation of the results from the parent study that would include continuing education credits.

Dental professionals. Before the enrollment of caregiver-child participants, dental staff (i.e., dentists, dental hygienists, and dental assistants) were consented into the study. After consenting, dental staff completed a demographics form. After each family appointment, dental staff completed the Frankl Scale. At the end of recruitment, dental staff completed the Dental Staff Acceptability Questionnaire. 
Caregivers and children. Caregiver-child dyads that expressed interest in the study were briefly screened to determine eligibility. All caregiver-child dyads who met inclusion criteria were invited to participate. Caregiver-child dyads were consented prior to starting the dental visit and then completed pre-appointment measures (i.e., SUDS, Wong-Baker FACES). Next, each participant's dental appointment was filmed using a small mounted video camera (i.e., ZOOM Q2n); furthermore, research personnel were not present during appointments and providers were encouraged to conduct appointments as per usual. After the dental appointment, caregivers were given a battery of post-appointment measures, debriefed, and compensated. Caregivers-child dyads received a gift card (\$25) and children's book (Peterson, 2018) for the completion of all aspects of the study per child.

Video transcripts. All video recordings of dental appointments were transcribed by research personnel to include both verbalizations and behaviors (e.g., caregiver: "Please sit on the chair" [caregiver places child on chair]). The primary investigator used a Cascading Model (CM; also known as train-the-trainer model) to train undergraduate researchers in the transcribing protocols (Herschell et al., 2015). This method used a hierarchal approach, in that two advanced transcribers were trained by a senior researcher (e.g., expert) via modeling, direct practice, observation, and feedback. These two advanced transcribers replicated this training with second-generation transcribers, and periodically reviewed the transcripts of secondgeneration transcribers to ensure competence and fidelity. The senior researcher also provided on-going consultation with the two advanced trainers throughout the process. To aid in the transcription process, all transcribers received a 1-day didactic training on using the basic coding rules (e.g., complete thought rule, superfluous phrases) from the Dyadic Parent-Child Interaction Coding System, Fourth Edition (DPICS-IV; Eyberg, Chase, Fernandez, \& Nelson, 
2014). Transcribers were also quizzed in "Discriminating Statements" (Fernandez,

Chase, Eyberg, \& Nelson, 2015). All transcribers had access to DPICS Research (Eyberg, Nelson, Ginn, Bhuiyan, \& Boggs, 2013) and Clinical (Eyberg et al., 2014) manuals to assist in transcriptions.

\section{Measures}

Child Behavior Checklist (CBCL). The Child Behavior Checklist for Ages 1.5-5

(CBCL; Achenbach \& Rescorla, 2001) is a measure of various internalizing and externalizing behaviors in young children. Caregivers provide ratings on 99 problem items scored on the following syndrome scales: Emotionally Reactive, Anxious/Depressed, Somatic Complaints, Withdrawn, Attention Problems, Aggressive Behavior, and Sleep Problems. Items are also scored on the following DSM-oriented scales: Affective Problems, Anxiety, Problems, Pervasive Developmental Problems, Attention Deficit/Hyperactivity Problems, Stress Problems, Autism Spectrum Problems, and Oppositional Defiant Problems. Caregiver reports on how true a statement is in describing his or her child over the past two months from not true (0), somewhat or sometimes true (1), or very true or often true (2). Many studies using the CBCL have demonstrated strong psychometric properties (de la Osa, Granero, Trepat, Domenech, \& Ezpeleta, 2016; Ivanova et al., 2007; Kariuki, Abubakar, Murray, Stein, \& Newton, 2016; Kristensen, Henriksen, \& Bilenberg, 2010; Tan, Dedrick, \& Marfo, 2007). The CBCL demonstrated good test-retest reliability $(r=.68$ to $r=.92)$ and adequate cross-informant agreement ( $r=.61$; Achenbach \& Rescorla, 2001). Kariuki et al. (2016) demonstrated internal consistency at $\alpha=0.95$.

There are three major subscales in the CBCL: Internalizing, Externalizing, and Total Problems. The present study incorporated the Internalizing, Externalizing, and Total Problems T- 
scores to describe the sample and explore associations among caregiver and child dental fear, child distress, child pain, and child behavior during dental appointments.

Demographic Information Forms. Basic demographic information for caregivers and children was collected utilizing the Caregiver Demographic Form and Child Demographic Form (see Appendix A). Demographic information for caregivers within the form contains items like race/ethnicity, gender, age, level of education, employment, and household income. In addition to similar items found on the caregiver form, the child form contains items on medications, psychiatric diagnoses, insurance, and information on previous dental visits.

Dental Fear Survey (DFS). The Dental Fear Survey (DFS; Kleinknecht, Klepac, \& Alexander, 1973) is a 20-item self-report instrument measuring overall caregiver dental fear. The DFS contains psychometric data attesting to its validity and reliability; it has been used with a number of unique cultural groups (McGlynn, McNeil, Gallagher, \& Vrana, 1987; Milgrom, Kleinknecht, Elliott, Hsing, \& Choo-Soo, 1990). Kleinknecht, Thorndike, McGlynn, and Harkavy (1984) conducted a factor analysis of DFS scores and found items loaded onto three factors: (a) dental avoidance and private fear behaviors associate with keeping a dental appointment, (b) private fear behaviors associated with dental stimuli and procedures, (c) reported physiological arousal during dental treatment. The DFS has strong test-retest reliability and internal consistency demonstrated with high Cronbach's alpha coefficients within total and subscale scores (McGlynn, 1987). Research supports the usage of the DFS in dentally fearful patients and nonclinical research subjects (McGlynn, 1987).

Dental Subscale of the Children's Fear Survey (CFSS-DS). The Dental Subscale of the Children's Fear Survey (CFSS-DS; Cuthbert \& Melamed, 1982) is a 15-item caregiver-report instrument measuring child dental care-related anxiety and fear. Caregivers rate their child's 
reactions on a five-point Likert-type scale ranging from not afraid at all (1) to very afraid (5). Low scores indicate less child dental care-related anxiety and fear; while, higher scores indicate more child dental care-related anxiety and fear. Previous research has demonstrated clinical cutoffs for dental anxiety scores to be equal to or exceeding 37, 38, or 39 on the CFSS-DS (Cuthbert \& Melamed, 1982; Klingberg \& Broberg, 2007).

\section{Dyadic Parent-Child Interaction Coding System, Fourth Edition (DPICS-IV).}

Dyadic Parent-Child Interaction Coding System, Fourth Edition (DPICS-IV; Eyberg, Chase, Fernandez, \& Nelson, 2014) is an observational measure of parent-child verbal interactions and responses. Coders trained in the DPICS transcribed the interactions and coded behavioral categories. Coders recorded the following behavioral categories: neutral talk (TA), direct command (DC), indirect command (IC), unlabeled praise (UP), labeled praise (LP), behavioral description (BD), reflection (RF), question (QU), negative talk (NTA), and child compliance (CO), child noncompliance (NC), child no opportunity for compliance (NOC), and child no opportunity for compliance from other (NOCO; see table 1). The DPICS coding system is exhaustive, in that all verbalizations are coded into one of the aforementioned categories. DPICS was used to measure parent's use of labeled praise, negative talk, direct commands, indirect commands, and child compliance. To create standardized scores, the frequency counts for a single DPICS category was transformed into a ratio. Ratios were created by taking the total frequency count of a single DPICS category and dividing it by the total count of DPICS codes.

Psychometrics. With over 30 years of research, the DPICS is an established coding system used to predict child cooperative behavior based on parent behaviors (Eyberg, Nelson, Ginn, Bhuivan, \& Boggs, 2013; Robinson \& Eyberg, 1981). In both live settings and video recorded observations, the DPICS categories have been shown to be reliable and valid (Eyberg et 
al., 2013). Robinson and Eyberg (Robinson \& Eyberg, 1981) found high average inter-rater reliability for child (.92) and parent behaviors (.91). One recent study by Shanley and Niec (2011) reported kappa value ranges for parent categories (.80 to 1.00$)$ and child categories (.80 to .98). Eyberg, et al. (2013) also reported the following DPICS kappa reliabilities: negative talk (.69), direct command (.82), indirect command (.66), labeled praise (.61), unlabeled praise (.81), information question (.85), descriptive question (.81), reflection (.59), behavior description (.60), neutral talk (.70), compliance (.64), noncompliance (.54), and no opportunity for compliance $(.54)$.

Procedure. Caregiver and child behavior during dental appointments were coded by undergraduate research assistants using the Dyadic Parent-Child Interaction Coding System (DPICS-IV; Eyberg, Chase, Fernandez, \& Nelson, 2014), and the reliability of the observational coding was examined. Twenty-five percent of caregiver-child DPICS observations during dental appointments was double-coded for reliability using the kappa statistic. All caregiver-child statements were coded in the transcription while viewing the videotape. If kappas were below .60 for a code of interest for a participant, discrepant codes were reviewed and the tape was recoded. For this study, no tape had to be recoded due to low kappas.

The primary investigator used a number of methods to reliably train coders in the DPICS (Eyberg et al., 2014). First, coders all attended either an intensive 3-hour long DPICS training or a 3-day DPICS training led by the primary investigator. After training, coders who attended the intensive 3-hour long DPICS training worked in dyads with advanced coders (i.e., coders who attended the 3-day DPICS training or had extensive prior DPICS coding experience). This method used a hierarchal approach that allowed advanced coders to provide direct support, observation, feedback, and consultation. Both trainings included a series of 
didactics, video review, and evaluations. Coders were evaluated at trainings and routinely after using exercises and quizzes from the Dyadic Parent-Child Interaction Coding System (DPICS) Clinical Workbook (Fernandez et al., 2015). Advanced coders and the primary investigator reviewed quiz answers with coders, and spent extra time reviewing coding rules for those who scored less than $80 \%$ correct. Coders needed to score above $80 \%$ on at least four of six quizzes (Fernandez et al., 2015).

The primary investigator also created a shared document to track frequently encountered DPICS rules to assist with coding (see Appendix B). Additionally, coders would record coding questions in a shared document for the primary investigator to address during weekly meetings. This shared decision rules DPICS document structured the iterative process of applying the DPICS to dental appointments involving multiple participants (e.g., caregiver, child, dentist, dental hygienist, and sibling). Once a coding question was answered, it was never removed from the decision rules table (see Appendix C). All coders had access to DPICS Research (Eyberg et al., 2013) and Clinical (Eyberg et al., 2014) manuals to assist in coding.

Any coders tasked with coding child compliance received a 1-hour didactic training from the primary investigator following the DPICS Research Manual (Eyberg et al., 2013). For the triadic nature of these dental appointments, the primary investigator added an additional code: no opportunity for compliance from other (NOCO). This new code, NOCO, was coded under the condition that the child was not given an adequate chance to comply with a command due to an individual other than the one who issued the initial command interfering with compliance. For example, a caregiver issues a command to the child and a dental provider immediately issues another command prior to the child complying with the caregiver's command. When a command was followed by another command from a different individual, within 5 seconds from the first 
command, the first command was automatically coded NOCO. The child's response to the second command was coded, and the child's response to the first command was coded NOCO.

Inter-coder agreement. An interrater reliability analysis using the kappa statistics was conducted to assess the consistency among raters across caregiver-child DPICS codes and child compliance codes. Inter-rater agreement was attained for approximately $26 \%$ of participants (i.e., 29 of 111 DPICS coded participants). Following DPICS rules regarding complete thought verbalizations, kappas were calculated line by line for all 29 participants. Qualitative descriptors of kappa statistics are also included below for clarity (Landis \& Koch, 1977).

For caregiver-child DPICS codes $(N=12,932$ lines), overall agreement was substantial between two coders, $\kappa=.785$ (95\% CI, .784 to .785), $p<.001$. The following specific DPICS variables had almost perfect agreement (i.e., above 0.81): UP ( $\kappa=.893$ [95\% CI, .892 to .893], $p$ $<.001), \mathrm{DC}(\kappa=.884[95 \% \mathrm{CI}, .884$ to .885$], p<.001)$, and QU $(\kappa=.904$ [95\% CI, .904 to $.905], p<.001)$. The following specific DPICS variables had substantial agreement (i.e., .61 to $.80): \mathrm{IC}(\kappa=.735$ [95\% CI, .734 to .735$], p<.001), \mathrm{LP}(\kappa=.628$ [95\% CI, .628 to .629], $p<$ $.001)$, NTA $(\kappa=.722$ [95\% CI, .722 to .723], $p<.001), \mathrm{RF}(\kappa=.724$ [95\% CI, .723 to .724$], p<$ $.001)$, and TA $(\kappa=.788$ [95\% CI, .788 to .789], $p<.001)$. Finally, there was moderate agreement (i.e., .41 to .60$)$ between coders on $\mathrm{BD}, \kappa=.463(95 \% \mathrm{CI}, .463$ to .464$), p<.001$. Thus, no codes had kappa statistics within fair (i.e., 21 to .40), slight (i.e., 0 to .20), or poor ranges (i.e., below $0)$.

For child compliance codes $(N=265)$, overall agreement was also substantial between two coders, $\kappa=.783(95 \% \mathrm{CI}, .780$ to .785$), p<.001$. Two child compliance codes had almost perfect agreement (i.e., above 0.81): $\mathrm{CO}(\kappa=.856$ [95\% CI, .852 to .859], $p<.001)$ and NOCO $(\kappa=.884[95 \% \mathrm{CI}, .880$ to .888$], p<.001)$. The other two had substantial agreement (i.e., .61 to 
$.80): \mathrm{NOC}(\kappa=.771[95 \% \mathrm{CI}, .767$ to .775$], p<.001)$ and $\mathrm{NC}(\kappa=.676$ [95\% CI, .672 to .680], $p<.001)$. Thus, no codes had kappa statistics within or below the moderate agreement range (i.e., below .60).

Frankl scale. The Frankl behavioral rating scale (Frankl scale; Frankl et al., 1962) measures child's behavior via dental provider report. The dental provider rates child behavior on a four-point Likert-type scale ranging from definitely negative (1) to definitely positive (4). Low scores indicate behaviors such as refusal of treatment and forceful crying; while, higher scores indicate behaviors such as laughter and enjoyment. The Frankl scale is routinely used in dental practice and research; however, Al-Namanknay, Souze, and Ashley (2012) reviewed the pediatric dental anxiety measures and found no studies providing validity or reliability evidence for the Frankl scale. In one study, 107 pediatric dental patients in private practice and clinic settings under the age of 6 demonstrated moderate Frankl correlations between dentists and other dental providers $(r=.63, p<.01)$. Additionally, child dental fear was positively related to the Frankl score $(r=.46, p<.001)$, and no relation was found between Frankl scores and child traitbased internalizing or externalizing behaviors (McNeil et al., 2019). This provides support that the Frankl score may reflect child dental care-related fear and anxiety in young children, rather than other behavioral issues.

A single, minimum Frankl behavioral rating scale score was calculated by using the lowest Frankl score between the attending dentist and dental hygienist for each participant. This minimum Frankl behavioral rating scale score was a measure of the child's most disruptive behavior during the dental appointment.

Subjective Units of Distress Scale (SUDS). The Subjective Units of Distress Scale (SUDS; Wolpe, 1969) is a measure of subjective intensity of distress experienced by a child via 
caregiver-report. The SUDS scale contains 11-points ranging from calm, totally relaxed (0) to highest distress/fear/anxiety/discomfort (100). This measure was given prior to the appointment and immediately following the appointment. Post-appointment assessment had caregivers rate their child's maximum distress during the appointment.

Wong-Baker FACES Pain Rating Scale (FACES). The Wong-Baker FACES Scale (FACES; Wong \& Baker, 1988) is a self-report measure of child pain. The FACES scale has a 6point scale ranging from not hurt (0) to hurts worst (10) that also contains visual anchors for each item (e.g., smile face, crying frown face). This measure was given prior to the appointment and immediately following the appointment. Post-appointment assessment had caregivers rate their child's maximum distress during the appointment.

\section{Results}

\section{Sample Characteristics}

Caregiver-report questionnaires provided demographic information for caregivers and children, such as sex, ethnicity, household income, and education. Demographic questionnaires provided descriptive data for the overall sample characteristics. Information was collected on 140 child participants via caregiver-report prior to treatment (i.e., pre-appointment SUDS and pre-appointment FACES) and post-treatment (e.g., demographic questionnaire). Caregivers in the sample averaged 33.3 years of age $(S D=7.71)$, and the majority were female $(88.5 \%)$, White (71.2\%), and few were of Hispanic/Latino ethnicity (2.9\%). Most caregivers were mothers $(83.5 \%)$; although, the sample contained some fathers $(10 \%)$ and other caregivers $(6.4 \%)$. Caregivers were predominately married (67.9\%) and the majority had at least a high school diploma or GED (95.8\%). Most caregivers reported a household size of four (31.4\%); nearly two-thirds of the sample (64.2\%) were above the poverty threshold for a family of four (i.e., 
\$25,750; “United States Department of Health and Human Services", 2019). Please see Table 2 for additional caregiver sample characteristics.

Children in the sample averaged 3.1 years of age $(S D=1.47)$, were predominately White (69\%), and few were of Hispanic/Latino ethnicity (4.3\%). Few children were below one year of age (2.9\%); however, approximately $14 \%$ were one year, $22 \%$ were two years, $18 \%$ three years, $20 \%$ were four years, and $22 \%$ were five years. Most children in the sample did not have a diagnosis of autism spectrum disorder (97.9\%), attention deficit hyperactivity disorder (96.4\%), or intellectual disability/developmental delay (94.3\%); few children were indicated as having a great deal of separation anxiety (10.7\%). A quarter of children (25\%) had no previous dental experiences; however, some children had previous dental visits: $22.1 \%$ had one, $17.6 \%$ had two, $12.5 \%$ had three, $12.5 \%$ had four, nearly $3.7 \%$ had five, and $6.6 \%$ had six or more previous dental visits. There were 47 caregiver-child dyads with a sibling also enrolled in the study; specifically, there were 22 caregiver-child dyads with a single sibling enrolled, and 1 caregiverchild dyad with two siblings enrolled. Please see Table 3 for additional child sample characteristics.

Providers were recruited from eleven clinics across three different states within West Virginia, Tennessee, and Ohio, and included community-based dental clinics, general dentistry practices, and pediatric dentistry practices. Providers in the sample $(\mathrm{N}=53)$ averaged 38.04 years of age $(S D=12.56)$, most were White $(80.9 \%)$, and few were of Hispanic/Latino ethnicity (6.4\%). Over half of providers were general dentists (28.6\%), nearly half were dental hygienists (24.5\%), and many were dental assistants (40.8\%). Providers worked on average 34.55 hours per week, and over half of providers worked full-time (60.4\%).

\section{Missing and Preliminary Analyses}


First, item-level missing analyses were conducted on the Dental Subscale of Children's Fear Survey (CFSS-DS) and Dental Fear Survey (DFS). For the CFSS-DS, Little's MCAR test was not significant ( $p=.765)$; the data were considered to be missing completely at random. One case was identified with $46.7 \%$ missingness, and excluded from CFSS-DS total score calculations because the participant skipped a page. Thus, a subsample $(n=139)$ of participants contain CFSS-DS total scores.

For the DFS, the data were considered to be missing completely at random because Little's MCAR test was also not significant $(p=.379)$. Only two cases contained missing items and none were above 2 items (i.e., $10 \%$ missing). Thus, the total sample $(N=140)$ of participants contain DFS total scores.

Missing analyses were then conducted on minimum Frankl behavior scale scores, CFSSDS total scores, and DFS total scores. For these three variables, the data were considered to be missing completely at random because Little's MCAR test was also not significant $(p=.795)$. Caregiver dental fear as measured by the DFS averaged $35.5(M=17.54)$. Child dental fear as measured by the CFSS-DS averaged $32.56(M=12.28)$.

Missing analyses were also conducted on caregiver-child DPICS interaction codes (i.e., LP, UP, IC, DC, QU, NTA, RF, BD, TA, and Complete Thought). In the subsample of coded videos $(n=111)$ there were no missing values. Participants videos not included in analyses $(n=$ 29) had videos with either technical errors (e.g., missing sound) or language barriers (e.g., caregiver-child talk was in a language other than English).

\section{Child Fear and Child Behavior}


Child fear. Child dental fear was hypothesized to be negatively correlated with positive child behavior during dental appointments. A nonparametric correlation was used along with pairwise deletion for missing values $(n=139)$.

Results. CFSS-DS and Frankl scale scores had a statistically significant negative association, $r_{s}=-.392, p<.001$, such that higher child dental fear was related to less positive behavior on the Frankl.

Frankl scale with four levels. Children with higher child dental fear were hypothesized to be significantly more likely to be classified as having poorer behavior during a dental appointment. The predictor variable in this model was the CFSS-DS. The ordinal Frankl behavioral scale scores was the outcome variables in this ordinal logistic model.

Assumption testing. Ordinal regression analyses were completed to determine whether the odds of child behavior differed significantly for different child dental fear scores. Before running an ordinal logistic model, cells were examined for appropriate size. Appropriate cell size was tested by checking a contingency table of independent (i.e., CFSS-DS total scores) and dependent variables (i.e., minimum Frankl behavioral scores). Case processing summary indicated adequate numbers as no level had very few cases in it (i.e., definitely negative [14; $10.0 \%]$, negative [26; $18.6 \%]$, positive $[71 ; 50.7 \%]$, and definitely positive $[29 ; 20.1 \%])$. Thus, the appropriate cell size was met to run an ordinal logistic regression.

The proportional odds assumption was tested to verify that the relationship between each pair of outcome groups is the same. Because the relationship between all pairs of groups is the same, there is only one set of coefficients. The test of parallel lines was not significant, $X^{2}(2, N$ $=140)=0.522, p=.77$; thus, there is no significant difference in the coefficients between models and no violation of the proportional odds assumption. 
Results. The predictor variable, CFSS-DS, in the ordinal logistic regression analysis was found to contribute to the model. Overall the model fit reveals a relationship between child dental fear and child behavior, $X^{2}(1, n=139)=22.907, p<.001$. Goodness-of-fit statistics test whether the observed data are consistent with the fitted model; the data and the model predictions are similar and demonstrate the model fits the data well, $X^{2}(1, n=139)=123.05, p=$ .677 . The Nagelkerke $\mathrm{R}^{2}$ value indicates the model accounts for $16.7 \%$ of the variance in child behavior during dental appointments. Parameter estimates provide information on the relationship between child dental fear and child behavior during dental appointments. A one unit increase in CFSS-DS was significantly associated with a decrease in the odds of having very positive behavior (i.e., Frankl score), with an odds ratio of 0.94 (95\% CI, 0.91 to 0.96), Wald $X^{2}$ $(1)=21.98, p<.001$. The odds of the definitely positive Frankl score category versus the combined positive, negative, and definitely negative Frankl score categories are 0.94 greater, given that all other variables in the model are held constant, with a one unit increase in CFSS-DS scores. Simply, lower CFSS-DS scores represent a protective factor for definitely positive dental appointments.

For children with definitely positive dental appointments, the odds of having a more negative dental appointment (i.e., positive, negative, or definitely negative compared to definitely positive) is $6 \%$ (i.e., $1-0.94)$ greater with each unit increase in CFSS-DS scores, holding constant all other variables. Furthermore, the ordered log negative cumulative logits demonstrate that higher CFSS-DS values were associated with lower Frankl scores (see Table 4).

Frankl scale with two levels. Children with higher dental fear were hypothesized to have increased odds of having negative behavior during dental appointments relative to children with 
lower dental fear. The predictor variable in this model was the CFSS-DS. The dichotomized Frankl behavioral scale was the outcome variable in this binary logistic model.

Assumptions. Before running a binary logistic model, cells were examined for appropriate size. Appropriate cell size was tested by checking a contingency table of independent (i.e., CFSS-DS total scores) and dependent variables (i.e., minimum Frankl behavioral scores); $139(100 \%)$ of Frankl behavioral scale cells (i.e., negative and positive) had observed counts above 5, with the lowest being 40 (i.e., negative Frankl scores). Thus, the appropriate cell size was met to run a binomial logistic regression.

Results. A logistic regression was preformed to ascertain the effects of CFSS-DS on the likelihood that children have negative Frankl scores. 92.9\% of children with positive Frankl scores were correctly classified, with $75.5 \%$ correctly classified overall, $\chi^{2}(1)=19.44, p<.001$. Negelkerke $\mathrm{R}^{2}$ demonstrated good fit indicated by a value of .187. CFSS-DS was found to be a significant predictor of likelihood of having positive Frankl scores, Wald test $=16.64, p<.001$. For each unit increase in CFSS-DS scores children were 7\% more likely to have negative Frankl scores (See Table 5).

Frankl scale with two levels on CFSS-DS cut-scores. Children with clinical dental fear were hypothesized to have increased odds of having negative behavior during dental appointments relative to children with non-clinical dental fear. The predictor variable in this model was the CFSS-DS dichotomized into clinical dental fear (i.e., score of 37 or higher) and nonclinical dental fear (i.e., CFSS-DS cut-scores). The dichotomized Frankl behavioral scale was the outcome variable in this binary logistic model.

Assumptions. Before running a binary logistic model, cells were examined for appropriate size. Appropriate cell size was tested by checking a contingency table of independent 
(i.e., CFSS-DS total scores) and dependent variables (i.e., minimum Frankl behavioral scores). For dichotomized Frankl behavioral scale, 139 (100\%) cells had observed counts above 5, with the lowest being 40 (i.e., negative Frankl). For dichotomized CFSS-DS, 139 (100\%) cells had observed counts above 5, with the lowest being 44 (i.e., clinical CFSS-DS). Furthermore, the lowest cell size was 19 (i.e., negative Frankl and nonclinical CFSS-DS). Thus, the appropriate cell size was met to run a binomial logistic regression.

Results. A logistic regression was preformed to investigate the effect of clinical CFSSDS on the likelihood that children have negative Frankl score. 100\% of children with positive Frankl scores were correctly classified, with $71.2 \%$ correctly classified overall, $\chi^{2}(1)=10.86, p$ $=.001$. Negelkerke $\mathrm{R}^{2}$ demonstrated moderately good fit indicated by a value of .108 . CFSS-DS cut-score was found to be a significant predictor of likelihood of having a negative Frankl scores, Wald test $=10.70, p=.001$. Those who had a CFSS-DS score of 37 or higher were 3.65 times more likely of having negative Frankl scores than those who had a CFSS-DS score below 37 (See Table 6).

CFSS-DS in positive and negative appointments. Children with positive behavior compared to negative behavior during dental appointments were hypothesized to not be equal across caregiver reports of child dental fear. The predictor variable in this model was the dichotomized Frankl behavioral scale (i.e., positive or negative). The CFSS-DS was the outcome variables in this model. An independent samples t-test was conducted to compare children who received positive versus negative Frankl behavioral scores on CFSS-DS total scores.

Assumptions. Data were evaluated for problems with normality, outliers, and homogeneity of variances. CFSS-DS total score was positively skewed $\left(\left|Z_{\text {skewness }}\right|=4.58\right)$. Data were run with and without a logarithmically transformed CFSS-DS total score. Because the 
logarithmically transformed CFSS-DS had no influence on the data, results of a t-test with no logarithmic transformations is reported. To assess the homogeneity of variance assumption, Levene's Test for equality of variances was examined. Levene's test of equality of variances was not significant using an alpha level of .05 $(p=.07)$; thus, the homogeneity of variances assumption was not violated.

Results. Significant differences were found on CFSS-DS between those who received positive Frankl scores $(M=29.6)$ and those who received negative Frankl scores $(M=39.8), t$ $(137)=4.97, p<.001$.

\section{Caregiver Fear and Child Behavior}

Caregiver fear. Caregiver dental fear was hypothesized to be negatively correlated with positive child behavior during dental appointments. A nonparametric correlation was used along with pairwise deletion for missing values $(N=140)$.

Results. DFS and Frankl scale scores were not significantly associated, $r_{s}=.098, p=$ .248

Frankl scale with four levels. Children of caregivers with high dental fear were hypothesized to be significantly more likely to be classified as having poorer behavior during a dental appointment. The predictor variable in this model was the DFS. The ordinal Frankl behavioral scale was the outcome variable in this ordinal logistic model.

Assumption testing. An ordinal regression analysis was completed to determine whether the odds of child behavior differ significantly for different caregiver dental fear scores. Before running an ordinal logistic model, cells were examined for size. Appropriate cell size was tested by checking a contingency table of independent (i.e., DFS total scores) and dependent variables (i.e., minimum Frankl behavioral scores). Case processing summary indicated adequate numbers 
as no level had very few cases in it (i.e., definitely negative $[14 ; 10.0 \%]$, negative $[26 ; 18.6 \%]$, positive $[71 ; 50.7 \%]$, and definitely positive $[29 ; 20.7 \%])$. Thus, the appropriate cell size was met to run an ordinal logistic regression.

The proportional odds assumption was tested to verify that the relationship between each pair of outcome groups is the same. Because the relationship between all pairs of groups is the same, there is only one set of coefficients. The test of parallel lines was not significant, $\mathrm{X}^{2}(2, N$ $=140)=0.522, p=.84$; thus, there is no significant difference in the coefficients between models and no violation of the proportional odds assumption.

Results. The predictor variable, DFS, in the ordinal logistic regression analysis was not found to contribute to the model. Overall the model fit does not demonstrate a relationship between caregiver dental fear and child behavior, $X^{2}(1,140)=0.671, p=.413$. Goodness-of-fit statistics test demonstrate the model fits the data well, $X^{2}(131, n=140)=134.21, p=.406$. The Nagelkerke $\mathrm{R}^{2}$ value indicates the model accounts for $0.5 \%$ of the variance in child behavior during dental appointments. A one unit increase in DFS was not significantly associated with a decrease in the odds of having very positive behavior (i.e., Frankl score), with an odds ratio of 1.01 (95\% CI, 0.99 to 1.03$)$, Wald $X^{2}(1)=0.635, p=.425$.

Frankl scale with two levels. Children of caregivers with higher dental fear were hypothesized to have increased odds of having negative behavior during dental appointments relative to children with lower dental fear. The predictor variable in this model was the DFS. The dichotomized Frankl behavioral scale was the outcome variables in this binary logistic model.

Assumptions. Before running a binary logistic model, cells were examined for appropriate size. Appropriate cell size was tested by checking a contingency table of independent (i.e., DFS total scores) and dependent variables (i.e., minimum Frankl behavioral scores); 140 
(100\%) of Frankl behavioral scale cells (i.e., negative and positive) had observed counts above 5, with the lowest being 40 (i.e., negative Frankl scores). Thus, the appropriate cell size was met to run a binomial logistic regression.

Results. A logistic regression was conducted to discover the effects of DFS on the likelihood that children have negative Frankl scores. The overall model was not significant, $\chi^{2}$ $(1)=1.15, p=.284$. Negelkerke $\mathrm{R}^{2}$ demonstrated poor fit indicated by a value of .012 . DFS was not found to be a significant predictor of likelihood of having positive Frankl scores, Wald test $=$ $1.06, p=.304($ See table 7$)$

DFS in positive and negative appointments. Children with positive behavior compared to negative behavior during dental appointments were hypothesized to not be equal across levels of caregiver dental fear. The predictor variable in this model was the dichotomized Frankl behavioral scale. The DFS was the outcome variable in this model. An independent samples ttest was conducted to compare children who received positive versus negative Frankl behavioral scores on DFS total scores.

Assumptions. Data were evaluated for problems with normality, outliers, and homogeneity of variances. DFS total score was positively skewed $\left(\left|Z_{\text {skewness }}\right|=8.82\right)$ and positively kurtotic $\left(\left|Z_{\text {kurtosis }}\right|=7.99\right)$. Data were run with a logarithmically transformed DFS total score. After the log transformation the distribution of DFS total score was improved $\left(\left|Z_{\text {skewness }}\right|=\right.$ 4.29) and $\left(\left|Z_{\text {kurtosis }}\right|=0.32\right)$. Results of a t-test with logarithmic transformations are reported. To assess the homogeneity of variance assumption, Levene's Test for equality of variances was examined. Levene's test of equality of variances was not significant using an alpha level of .05 $(p=.70)$; thus, the homogeneity of variances assumption is not violated. 
Results. No significant difference was found on DFS between those who received positive Frankl scores $(M=1.52)$ and those who received negative Frankl scores $(M=1.48), t$ $(138)=-1.156, p=.249$.

\section{Caregiver-Child Interactions and Child Behavior}

Labeled praise. Caregiver use of labeled praise directed at his or her child was hypothesized to be positively correlated with positive behavior during dental appointments. Caregiver ratio of labeled praise and Frankl behavioral scale scores were correlated to investigate this relationship.

Results. Caregiver ratio of labeled praise and child Frankl scores were not significantly associated, $r_{s}=.179, p=.060$.

Negative talk. Caregiver use of negative talk directed at his or her child was hypothesized to be negatively correlated with positive child behavior during dental appointments. The relationship between caregiver ratio of negative talk and Frankl behavioral scale scores was examined to investigate this relationship.

Results. Caregiver ratio of negative talk and child Frankl scores were not significantly associated, $r_{s}=-.147, p=.123$; however, the directionality of the relationship was in the hypostasized direction.

Child compliance to direct and indirect commands. Child compliance to caregiver use of direct commands was hypothesized to be higher than child compliance to indirect commands. A paired sample t-test was conducted to demonstrate how child compliance differed in response to caregiver direct commands versus indirect commands. The dependent variable (i.e., child compliance) is continuous as it was measured as a ratio over caregiver's total use of (a) direct and (b) indirect commands. 
Assumptions. The non-parametric test was conducted in lieu of a paired samples t-test because the data were not normally distributed. Thus, a related-samples Wilcoxon signed rank test was conducted to determine differences in compliance between direct and indirect commands for each participant $(N=111)$.

Results. There was a significant difference in child compliance to direct commands and indirect commands. This is, child compliance with direct commands was significantly higher $(M d n=.25)$ than indirect commands $(M d n=.00), T=-3.92, p<.001$. Children complied on average to $28.5 \%$ of direct commands $(S D=.25)$; for indirect commands, children complied on average to $16.7 \%$. Interestingly, caregivers most frequently gave commands with no-opportunity for compliance: direct commands no-opportunity for compliance $(M=.47, S D=.29)$ and indirect commands no-opportunity for compliance $(M=.47, S D=.41)$.

\section{Exploratory Analyses}

Caregiver-child interactions, dental fear, and child behavior. Correlations were examined to determine which factors significantly contributed to variance for child behavior, during dental appointments, as measured by the Frankl behavioral scale (see Table 8). Variables of interest included the ratio of caregiver use of DPICS codes toward the child (i.e., LP, UP, IC, DC, QU, NTA, RF, BD, and TA), DFS scores, CFSS-DS scores, pre- and post-SUDS scores, pre- and post FACES scores, and CBCL T-scores (i.e., externalizing, internalizing, and total).

Results. Notably, child dental fear scores were significantly correlated with child behavior during dental appointments $\left(r_{s}=-.39, p<.001\right)$, child internalizing scores $(r=.29, p=$ $.001)$, pre-appointment distress $(r=.26, p=.002)$, and post-appointment distress $(r=.48, p<$ .001). Child behavior during dental appointments was also significantly correlated with post- 
appointment distress $\left(r_{s}=-.53, p<.001\right)$. Caregiver dental fear scores were significantly correlated with caregiver use of labeled praise $(r=.23, p=.015)$.

Child externalizing scores were significantly correlated with both negative talk $(r=.23, p$ $=.02)$ and child internalizing scores $(r=.63, p<.001)$; child CBCL total scores were also significantly related to child internalizing scores $(r=.79, p<.001)$ and child externalizing scores $(r=.83, p<.001)$. Post-appointment child pain was significantly associated with caregiver use of behavior descriptions $(r=.22, p=.026)$, child internalizing scores $(r=.21, p=.026)$, child externalizing scores $(r=.23, p=.015)$, and CBCL total scores $(r=.20, p=.032)$. Interestingly, post-appointment child distress was significantly related to pre-appointment child pain $(r=.28, p$ $=.002)$.

The present study was novel for sampling young children all below the age of 6 . Thus, it was important to include age within the exploratory correlation analyses. Interestingly, age was only significantly correlated with pre-appointment pain $(r=.17, p=.046)$ and child behavior during dental appointments $\left(r_{s}=.26, p=.002\right)$.

\section{Discussion}

\section{Summary of Findings}

The study sought to investigate the relationship between child behavior, child dental fear, and caregiver dental fear for children under six years during dental appointments. The results of the study indicated that higher rates of child dental fear were significantly associated with less positive child behavior during dental appointments. However, caregiver dental fear was not shown to be significantly associated with child behavior during dental appointments. The failure to find a possible connection between caregiver dental fear and child behavior during dental appointments may be related to variability with respect to measurement. While this study used an 
established measure of adult dental fear, future studies may benefit from incorporating a multimodal measurement of caregiver dental fear. Important findings in the current study involve various relationships between child dental fear, caregiver dental fear, caregiver-child interactions, and child behavior.

\section{Child Fear and Child Behavior}

Overall, child dental fear was significantly associated with child behavior during dental appointments. Specifically, a unit increase in child dental fear scores significantly increased the odds of having negative behavior during a dental appointment. Furthermore, for each unit increase in dental fear scores children were 7\% more likely to have negative behavior during their appointment. Thus, children with higher dental fear scores were more likely to have negative child behavior during dental appointments. Like the current study, previous research has demonstrated similar associations between child dental fear and dental behavior management problems (Klingberg \& Broberg, 2007).

Previous literature has shown $5.7 \%$ to $20 \%$ of children and adolescents, ranging in age from less than one to twelve, present with dental fear (Baier, Milgrom, Russell, Mancl, \& Yoshida, 2004; Klingberg \& Broberg, 2007). Three studies based prevalence rates off parental CFSS-DS, and with pooled prevalence rate of $6.3 \%$ (range $5.7 \%$ to $6.7 \%$; Klingberg \& Broberg, 2007). In the present sample, nearly $32 \%$ of children demonstrated high dental fear scores; that is, scores of 37 or greater on the CFSS-DS. The discrepancy in child dental fear prevalence rates may be related to CFSS-DS cut scores, sample size, and age.

First, the present study utilized a cut-score of 37 on the CFSS-DS. Research has demonstrated clinical cut-offs on the CFSS-DS to be equal to or exceeding 37, 38, or 39 (Cuthbert \& Melamed, 1982; Klingberg \& Broberg, 2007). Four studies based prevalence rates 
off of parental CFSS-DS scores used cut scores of 38 and 39 (Baier et al., 2004; Klingberg \& Broberg, 2007). Second, previous studies had sample sizes that ranged from 421 to 3,166 participants; whereas, the present sample had a sample size of 140 (Baier et al., 2004; Klingberg \& Broberg, 2007). Results from larger studies produce more precise results because the width of confidence intervals depend directly on the sample size. Thus, CFSS-DS cut-score points and sample size may contribute to differences in child dental fear prevalence estimates.

Perhaps most importantly, the discrepancy in the prevalence of child dental fear may be due to age. This study is one of the first to focus on young children under the age of six in dental settings. Research has indicated that young children (i.e., 6 years and younger) are 1.5 times as likely to have high dental fear as older children and adolescents (i.e., 7 to 12 years). Thus, young children under 6 years of age may present with more dental fear than older children. Bauer (1976) found structural variances in fears reflecting general developmental trends in young children; specifically, children between four and six years more frequently endorsed fears with imaginary themes (e.g., monsters), and older children more frequently endorsed fears involving bodily injury and physical danger. As a child ages, fear become more based on reality, which may explain why prevalence of dental fear decreases with age. Perhaps due to infection control procedures, wherein dental providers are required to wear surgical masks, very young children may be particularly fearful of providers whose masks may make them look more like monsters. For instance, an assessment of the distribution of visual attention using eye-tracking demonstrated that children fixated on the dentist's face, particularly the mouth (Celine, Cho, Kogan, Anthonappa, \& King, 2018). Importantly, if children are fixated on the mouth of dental providers, a mask may make the provider seem more frightening. At the very least, a mask restricts the providers' ability to smile, which makes it more difficult for the provider to build 
rapport, seem approachable, and engage in positive, nonverbal communication with young children.

After applying a dental fear cut-score (i.e., scores of 37 or greater on the CFSS-DS) to separate children into high and low dental fear groups, children with high dental fear were 3.65 times more likely to have negative behavior during a dental appointment. A similar study demonstrated children who were reported as fearful were 2.4 times as likely to behave negatively during dental appointments as non-fearful children (Baier et al., 2004). Like the current study, Klingberg et al. (1995) demonstrated that behavior management problems were more common in four to twelve year old children with dental fear (CFSS-DS scores of 38 or greater) than in children without dental fear. Specifically, of children with behavior management problems, $61.3 \%$ had high dental fear (Klingerberg et al., 1995). In the present study, of children with negative behavior during dental appointments 52.5\% had high dental fear scores. Thus, the connection between child dental fear and child behavior during dental appointments was supported by not only the present study, but previous literature also.

\section{Caregiver Fear and Child Behavior}

Although not a hypothesis, caregiver dental fear and child dental fear was, surprisingly, not significantly associated in the present study. In general, caregiver fearfulness has been positively associated with child fearfulness (Muris et al., 1996); in this study, researchers measured child fear in children ranging in age from nine to twelve years. Previous research supports a relationship between parental and child dental fear, especially for children eight years and under (Themessl-Huber et al., 2010); however, studies ranged widely with respect to design, methods, and the reported caregiver-child dental fear link. Although all studies including children under 8 years of age $(n=14)$ demonstrated a significant relationship between parental 
and child dental fear, only one study used established anxiety scales for both parents and children. The present study utilized established anxiety measures - CFSS-DS and DFS. It is possible that the inconsistent usage of established measures may account for this discrepant finding. Three studies that sampled children up to 10 years of age found no relationship between parental and child dental anxiety; these studies incorporated either established behavior rating or dental anxiety scales (Themessl-Huber, 2010).

Inconsistent with hypotheses, caregiver dental fear was not significantly related to child behavior during dental appointments. Research has demonstrated an association between parental and child dental fear through an investigation of etiological factors related to dental fear acquisition in children aged four to nine and nine to eleven (Klingberg et al., 1995). Precisely, general fears, maternal dental fear, and age were factors that significantly contributed to the development of dental fear in children (Klingberg et al., 1995). The failure to find a significant difference between groups (i.e., negative and positive child behavior) and caregiver dental fear may be related to the multifaceted etiology of child disruptive behavior. Not all children with behavior problems during dental appointments are necessarily dentally fearful and dental fear may not always present as noncompliance or disruptive behavior. Namely, child behavior problems during dental appointments are only partially explained by child dental fear.

Furthermore, the present study sought to demonstrate dental fear acquisition through vicarious learning experience of caregiver dental fear by only using a single established dental fear measure. According to Ollendick and King (1991), fear acquisition occurs in an integrated manner through direct conditioning, vicarious experiences, and modeling. Thus, reliance on a single measure of caregiver modeling of dental fear may limit the understanding of this finding. For instance, Milgrom et al. (1995) demonstrated a significant relationship between parental and 
child dental fear, specifically parental modeling of dental fear; however, this study measured parental modeling in multiple ways (i.e., DFS and oral health behavior). Use of a single established measure of caregiver dental fear may not fully capture the construct of caregivers modeling dental fear. Because of this, future research is encouraged to consider multiple methods of measuring caregiver modeling of dental fear beyond the DFS.

With a focus on early dental experiences, many children in this sample had never previously been to the dentist (25\%), fewer had been one time before $(22.1 \%)$, and even fewer had been two times before (17.6\%). The very young sample in the current study may simply have had insufficient exposure to caregiver transmission of fear during dental appointments to acquire similar fear patters. Thus, the preschool children in the present investigation, particularly those in the sample who were attending their first dental appointment, had fewer in-vivo modelling opportunities than the older children in previous samples who had experienced more dental visits. Caregiver dental fear likely manifests itself through verbalizations and behavior during dental visits. Thus, caregiver dental fear may be expected to play a larger role in the development and maintenance of child dental fear over time, when there are more opportunities for the child to encounter parental modeling of dental fear during actual dental experiences.

\section{Caregiver-Child Interactions and Child Behavior}

The present study is the first to investigate dyadic caregiver-child interactions using the DPICS during young child dental appointments. Although labeled praise was shown to be positively related to caregiver fear, the majority of caregivers are not giving any labeled praises (86.5\%), and only some caregivers give a single labeled praise during the dental appointment (10.8\%). Negative talk includes sarcasm and critical statements. Parental verbal abuse, which falls under negative talk, has been associated with increased conduct problems, physical 
aggression, interpersonal problems, problem behaviors, and internalizing symptoms (SachsEricsson et al., 2006). Although, the present study did not find a statistically significant association between negative talk and child behavior, negative talk was associated negatively with unlabeled praise $(r=-.30)$, positively with indirect commands $(r=.21)$, negatively with questions $(r=-.20)$, negatively with neutral talk $(r=-.20)$, and positively with CBCL externalizing T-scores $(r=.23)$. Thus, negative talk may be related to an overall communication style that is lower in warmth, less communicative, and more demanding. Furthermore, this study adds to the literature that negative talk is associated with externalizing behavior (Wang \& Kenny, 2014).

In light of previously discussed findings, caregiver-child interactions may still represent a pathway towards dental fear acquisition in young children. Caregiver-child interactions during early dental experiences integrate both direct conditioning and indirect conditioning pathways. For example, a parent may directly reinforce maladaptive coping strategies, such as escape and avoidance behavior. A parent may also reinforce that the dentist is a positive experience by using positive following behaviors and verbalizations that make dental appointments more fun and enjoyable. In the present study use of unlabeled praise was positively associated with behavior descriptions. Praise, behavior descriptions, and reflections comprise a set of positive following behaviors which provide children with highly rewarding caregiver attention (Eyberg, et al., 2013).

An important and novel finding from this study are the frequency and ratio of caregiverchild verbalizations during dental appointments. This most frequently used DPICS codes during young child dental appoints were neutral talk $(M=33.07, S D=39.22$, range $0-259)$, questions $(M=16.01, S D=23.89$, range $0-162)$, and direct commands $(M=17.18, S D=20.17$, range 0 - 
90). Thus, young children dental appointments consist primarily of chit-chat, questions, and direct commands. Furthermore, the present study demonstrated that young children during dental appointments significantly comply more often to direct commands than indirect commands from caregivers. This finding aligns with previous research, which found that specific parental commands increase child compliance (Forehand \& McMahon, 1981; Hembree-Kigin \& McNeil, 2013; Walker \& Walker, 1991).

\section{Limitations}

Caregiver and child participants were recruited from a limited number of locations across West Virginia, Ohio, and Tennessee. Although the samples were representative of the population from which they lived, the findings may not be representative of the broader population, which may limit the generalization of these findings. For instance, Raadal, Milgrom, Weinstein, Mancl, and Cauce (1995) found that CFSS-DS scores averaged 32.7 in a low-income population of children between the ages of five and eleven $(N=895)$. Although $64.2 \%$ of our sample was above the poverty threshold for a family of four, CFSS-DS scores averaged 32.5. Whereas, other population-based mean scores of the CFSS-DS range from 23.1 to 29.7 (Klingberg et al., 1995, Lee, Chang, \& Huang, 2007; Ten Berge, Veerkamp, Hoogstraten, \& Prins, 2002; Wogelius, Poulsen, \& Toft Sørensen, 2003).

To fully explore this rich naturalistic data set, analyses were run on all participants. Future studies should investigate family related factors during routine dental appointments. For instance, research should investigate differences between involving and not involving siblings in dental appointments. For convenience, families often arrange for all siblings to see that dentist at once. Siblings may help each other regulate emotions, engage in distraction, and model positive behavior during dental appointments; however, siblings may also escalate negative behavior and 
noncompliance. It is clinically important to understand how siblings influence dental appointments because it frequently happens in oral health care. A fruitful investigation might also be to study how larger family appointments differ from a single caregiver-child appointment. This may contribute vital knowledge that providers could incorporate into practice.

To reduce burden on providers and clinics, researchers had to limited pre-appointment measures in the present study to the SUDS and FACES. Caregiver-report of child dental fear was assessed post-appointment. Thus, caregiver perceptions of child negativity or positivity during the appointment may have confounded their later reports of child dental fear. Reporting on child dental fear after the session may have inflated the relationship between CFSS-DS and Frankl scores. Similarly, the post-appointment completion of some measures may have influenced the positive correlations between CFSS-DS and post-treatment SUDS. Future research should investigate whether order of CFSS-DS reporting influences the relationship between CFSS-DS and Frankl scores.

A factor to consider in the exploration of the relationship between caregiver-child interactions and child behavior during dental appointments is the reason for the child's dental visit. For instance, the type of appointment should be controlled because routine hygiene and restorative visits may produce situational characteristics that elicit and necessitate specific behaviors from caregivers. Future research would benefit from addressing the reason for the child's dental appointment as well as all previous visits to date. Ollendick and King (1991) found that fear acquisition pathways synergistically operate, and that it is necessary for (a) both vicarious and instructional conditioning or (b) vicarious and direct conditioning experiences to occur before high levels of fear are reported. 
Thus, it is important to tease apart current and past direct conditioning experiences from indirect conditioning experiences. Previous negative and painful experiences may confound the impact of caregiver modeling of dental fear. According to Rachman (1977), vicarious learning involves observational learning and modeling; thus, vicarious dental fear pathways may not work as quickly as direct conditioning pathways. The reason for the dental visit may serve as an important dependent variable or may need to be controlled statistically or methodologically in future studies of caregiver-child dental fear acquisition. Finally, prior direct conditioning experiences could place children at increased risk, wherein dental fear may not relate to child behavior or child dental fear unless the child has had a previous overt negative experience. Future research should investigate how these separate fear pathways relate to one another.

\section{Future Directions}

This study adds to the increasing literature on the connection between child dental fear and behavior management problems during dental appointments. Specifically, the present research found that children with high dental fear were 3.65 times more likely of having negative behavior during dental appointments than children with low dental fear. Providers ought to incorporate the CFSS-DS into routine practice to screen for children who are at increased risk of having negative dental appointments. This screening measure may also be useful in designing a strategic schedule of patients (e.g., alternating children with more and less fear) to maximize patient success and enhance clinic productivity. For instance, children with high dental fear scores may benefit from more gradual exposures to the dental environment (e.g., extra happy visits, specialized care) and may benefit from the extra time available at the beginning or the end of the day. Thus, providers may be able to use the CFSS-DS to improve workplace productivity by identifying patients likely to need extra care and time as well as those who may be easier to 
treat. A screening measure could be helpful in preventing and/or reducing childhood dental fear by allowing the staff to accommodate the special needs of individual children.

Future studies ought to incorporate multiple methods of assessing caregiver dental fear. The present study only used a single established measure (i.e., DFS). Focusing on how caregivers model dental fear might include an assessment of caregiver oral health. It may also include acquiring caregiver modeling behavior outside the immediate dental context (e.g., home dental behavior). By incorporating multiple methods of measuring caregiver dental fear, researchers may be able to help identify ways in which young children acquire dental fear. This knowledge may facilitate the development of interventions aimed at reducing dental fear at the individual and family-system level.

In addition to improving upon the measurement of caregiver modeling of dental fear, future studies should also investigate how caregiver-child interactions cluster. Identifying caregiver-child clusters may help to identify profiles of interaction patterns that relate to positive outcomes (i.e., low child dental fear and positive child behavior). Identifying profiles of caregiver-child interaction patterns related to positive outcomes may help with the identification of skills that ultimately could be used to train caregivers in methods shown to improve dental appointments. This type of clinical application research may lead to information and screening tools that could help providers to prevent child fear and intervene in an effective manner when disruptive behavior occurs during dental appointments. 


\section{References}

Achenbach, T. M., \& Rescorla, L. A. (2001). Manual for the ASEBA preschool forms \& profiles. Burlington, VT: University of Vermont, Research Center for Children, Youth, \& Families.

Al-Namankany, A., De Souza, M., \& Ashley, P. (2012). Evidence-based dentistry: Analysis of dental anxiety scales for children. British Dental Journal. doi:10.1038/sj.bdj.2012.174

American Academy of Pediatric Dentistry. (2011). Guideline on behavior guidance for the pediatric dental patient: Reference manual. AAPD Guideline, 36(6), 179-191.

American Academy of Pediatric Dentistry. (2013). Guideline on periodicity of examination, preventive dental services, anticipatory guidance/counseling, and oral treatment for infants, children, and adolescents. Pediatric Dentistry, 35(5), 123-130.

American Academy of Pediatric Dentistry. (2014). Guideline on infant oral health care. Pediatric Dentistry, 37(6), 146-150.

American Academy of Pediatric Dentistry. (2015). Guideline on behavior guidance for the pediatric dental patient. Pediatric Dentistry, 37(6), 180-193.

Armfield, J. M., Stewart, J. F., \& Spencer, A. J. (2007). The vicious cycle of dental fear: exploring the interplay between oral health, service utilization and dental fear. BMC Oral Health, 7(1), 1. doi:10.1186/1472-6831-7-1

Armfield, J. M. (2010). The extent and nature of dental fear and phobia in Australia. Australian Dental Journal, 55, 368-377. doi:10.1111/j.1834-7819.2010.01256.x

Armfield, J. M., \& Heaton, L. J. (2013). Management of fear and anxiety in the dental clinic: A review. Australian Dental Journal, 58, 390-407. doi:10.1111/adj.12118

Baier, K., Milgrom, P., Russell, S., Mancl, L., \& Yoshida, T. (2004). Children's fear and behavior in private pediatric dentistry practices. Pediatric Dentistry, 26(4), 316-321. 
Bandura, A. (1969). Principles of behavior modification. Oxford, England: Holt, Rinehart, \& Winston.

Bandura, A. (1971). Vicarious and self-reinforcement processes. In R. Glaser (Ed.), The nature of reinforcement (pp. 228-278). New York: Academic Press, Inc.

Bernhardt, A. J., \& Forehand, R. The effects of labeled and unlabeled praise upon lower and middle class children. Journal of Experimental Child Psychology, 1975, 19, 536-543. doi:10.1016/0022-0965(75)90082-X

Blane, D. (1999). The life course, the social gradient, and health. In M. Marmot, \& R. G. Wilkinson (Eds.), Social determinants of health (pp. 54-77). New York: Oxford University Press.

Carter, A. E., Carter, G., Boschen, M., AlShwaimi, E., \& George, R. (2014). Pathways of fear and anxiety in dentistry: A review. World Journal of Clinical Cases: WJCC, 2(11), 642653. doi:10.12998/wjcc.v2.i11.642

Celine, G., Cho, V., Kogan, A., Anthonappa, R., \& King, N. (2018). Eye-tracking in dentistry: What do children notice in the dentist?. Journal of Dentistry, 78, 72-75. doi:10.1016/j.jdent.2018.08.006

Cohen, S. M., Fiske, J., \& Newton, J. T. (2000). The impact of dental anxiety on daily living. British Dental Journal, 189(7), 385-390. doi:10.1038/sj.bdj.4800777

Craske, M. G. (2003). Why more women than men?. In Craske (Eds.), Origins of phobias and anxiety disorders (pp. 175-204). Oxford: Elsevier. doi:10.1016/B978-008044032$3 / 50000-9$

Cuthbert, M. I., \& Melamed, B. G. (1982). A screening device: Children at risk for dental fears and management problems. Journal of Dentistry for Children, 49, 432-436. 
de la Osa, N., Granero, R., Trepat, E., Domenech, J. M., \& Ezpeleta, L. (2016). The discriminative capacity of CBCL/11/2-5-DSM5 scales to identify disruptive and internalizing disorders in preschool children. European Child \& Adolescent Psychiatry, 25(1), 17-23. doi:10.1007/s00787-015-0694-4

Doerr, P. A., Lang, W. P., Nyquist, L. V., \& Ronis, D. L. (1998). Factors associated with dental anxiety. The Journal of the American Dental Association, 129(8), 1111-1119. doi:10.14219/jada.archive.1998.0386

Eyberg, S. M., Chase, R. M., Fernandez, M. A., \& Nelson, M. M. (2014). Dyadic parent-child interaction coding system (DPICS) clinical manual (4th ed.). PCIT International.

Eyberg, S. M, Nelson, M. M., Ginn, N. C., Bhuiyan, N., \& Boggs, S. R. (2013). Dyadic parentchild interaction coding system (DPICS) comprehensive manual for research and training (4th ed.). PCIT International.

Faul, F., Erdfelder, E., Buchner, A., \& Lang, A. G. (2013). G* Power Version 3.1. 7 [computer software]. Uiversität Kiel, Germany.

Felicione, N. J., Blank, M. D., Wright, C. D., McNeil, D. W., (2018). Pain, fear, anxiety, and stress: Relation to beta-endorphins. In P. Kerr \& C. Sirbu (Eds.), Endorphins: From Molecular Science to Modern Medicine. In press.

Fernandez, M. A., Chase, R. M., Eyberg, S. M., \& Nelson, M. M. (2015). Dyadic parent-child interaction coding system (DPICS) clinical workbook (4th ed.). PCIT International.

Forehand, R. L., \& McMahon, R. J. (1981). Helping the noncompliant child: A clinician's guide to parent training. New York: Guilford press.

Forehand, R., \& Scarboro, M. E. (1975). An analysis of children's oppositional behavior. Journal of Abnormal Child Psychology, 3(1), 27-31. doi:10.1007/BF00916027 
Frankl, S. N., Shiere, F. R., \& Fogels, H. R. (1962). Should the parent remain with the child in the dental operatory?. Journal of Dentistry for Children, 29, 150-163.

Funderburk, B. W., \& Eyberg, S. M. (2011). Parent-Child Interaction Therapy. In J. C. Norcross, G. R. VandenBos, \& D. K. Freedheim (Eds.), History of psychotherapy: Continuity and change (2nd ed., pp. 415-450). Washington, DC: American Psychological Association.

Hamzah, H. S., Gao, X., Yiu, C. K. Y., McGrath, C., \& King, N. M. (2014). Managing dental fear and anxiety in pediatric patients: A qualitative study from the public's perspective. Pediatric Dentistry, 36(1), 29-33.

Herschell, A. D., Kolko, D. J., Scudder, A. T., Taber-Thomas, S., Schaffner, K. F., Hiegel, S. A., ... \& Mrozowski, S. (2015). Protocol for a statewide randomized controlled trial to compare three training models for implementing an evidence-based treatment. Implementation Science, 10(1), 133. doi:10.1186/s13012-015-0324-z

Ivanova, M. Y., Achenbach, T. M., Dumenci, L., Rescorla, L. A., Almqvist, F., Weintraub, S., . . . Verhulst, F. C. (2007). Testing the 8-syndrome structure of the Child Behavior Checklist in 30 societies. Journal of Clinical Child and Adolescent Psychology, 36(3), 405-417. doi:10.1080/15374410701444363

Kariuki, S. M., Abubakar, A., Murray, E., Stein, A., \& Newton, C. R. J. C. (2016). Evaluation of psychometric properties and factorial structure of the pre-school child behaviour checklist at the Kenyan Coast. Child and Adolescent Psychiatry and Mental Health, 10, 1-10. doi:10.1186/s13034-015-0089-9

Kleinknecht, R. A., Klepac, R. K., \& Alexander, L.D. (1973). Origins and characteristics of fear of dentistry. Journal of the American Dental Association, 86, 842-848. doi:10.14219/jada.archive.1973.0165 
Kleinknecht, R. A., Thorndike, R. M., McGlynn, F. D., \& Harkavy, J. (1984). Factor analysis of the dental fear survey with cross-validation. Journal of the American Dental Association, 108(1), 59-61. doi:10.14219/jada.archive.1984.0193

Klingberg, G., Berggren, U., Carlsson, S. G., \& Noren, J. G. (1995). Child dental fear: causerelated factors and clinical effects. European Journal of Oral Sciences, 103(6), 405-412. doi:10.1111/j.1600-0722.1995.tb01865.x

Klingberg, G., \& Broberg, A. G. (2007). Dental fear/anxiety and dental behaviour management problems in children and adolescents: a review of prevalence and concomitant psychological factors. International Journal of Paediatric Dentistry, 17(6), 391-406. doi:10.1111/j.1365-263X.2007.00872.x

Klingberg, G., Löfqvist, L. V., Bjarnason, S., \& Norén, J. G. (1994). Dental behavior management problems in Swedish children. Community Dentistry and Oral Epidemiology, 22(3), 201-205. doi:10.1007/s40368-018-0346-8

Klingberg, G., Raadal, M., \& Arnrup, K. (2016). Dental fear and behavior management problems. In G. Koch, \& S. Poulsen (Eds.), Pediatric dentistry. A clinical approach. doi:10.1111/j.1365-263X.2007.00872.x

Kristensen, S., Henriksen, T. B., \& Bilenberg, N. (2010). The Child Behavior Checklist for ages 1.5-5 (CBCL/11/2-5): Assessment and analysis of parent- and caregiver-reported problems in a population-based sample of Danish preschool children. Nordic Journal of Psychiatry, 64(3), 203-209. doi:10.3109/08039480903456595

Landis, J. R., \& Koch, G. G. (1977). The measurement of observer agreement for categorical data. Biometrics, 159-174. doi:10.2307/2529310 
Lautch, H. (1971). Dental phobia. The British Journal of Psychiatry, 119(549), 151-158. doi:10.1192/bjp.119.549.151

Lieneman, C. C., Brabson, L. A., Highlander, A., Wallace, N. M., \& McNeil, C. B. (2017). Parent-Child Interaction Therapy: Current perspectives. Psychology Research and Behavior Management. doi:10.2147/PRBM.S91200

McGlynn, F. (1988). Dental Fear Survey. In Hersen, M. E., \& Bellack, A. S. (Eds.), Dictionary of behavioral assessment techniques (pp. 168-170). New York: Pergamon Press.

McGlynn, F., McNeil, D., Gallagher, S., \& Vrana, S. (1987). Factor structure, stability, and internal consistency of the Dental Fear Survey. Behav Assess, 9(1), 57-66.

McNeil, C. B., \& Hembree-Kigin, T. (2010). Parent-Child Interaction Therapy: Second Edition. New York: Springer. doi:10.1007/978-0-387-88639-8

McNeil, C. B., Owen, C. K., Eackles, K., Quetsch, L., Hickey, K., Lilly, C. L., Heima, M., \& McNeil, D. W. (2019, June). Frankl scores in the assessment of young child behavior during dental appointments. Poster presented at the International Association for Dental Research, Vancouver, British Columbia, Canada.

McNeil, D. W., \& Randall, C. L. (2014). Dental fear and anxiety associated with oral health care: conceptual and clinical issues. Behavioral Dentistry, 165-192. doi:10.1111/cdoe.12261

McNeil, D. W., Vargovich, A. M., Turk, C. L., \& Ries, B. J. (2012). Anxiety and fear. In V. S. Ramachandran (Ed.), Encyclopedia of human behavior: Vol. 1. (2nd ed., pp. 161-168). San Diego: Academic Press.

Mehrstedt, M., Tönnies, S., \& Eisentraut, I. (2004). Dental fears, health status, and quality of life. Anesthesia Progress, 51, 90-94. 
Melamed, B. G., \& Lumley, M. A. (1988). Dental subscale of the Children's Fear Survey Schedule. In M. Hersen \& A. S. Bellach (Eds.), Dictionary of behavioral assessment techniques (p. 171). Oxford: Pergamon.

Melamed, B. G., \& Williamson, D. J. (1991). Programs for the treatment of dental disorders. In J. J. Sweet, R. H. Rozensky, \& S. M. Tovian (Eds.), Handbook of clinical psychology in medical settings (pp. 539-565). Springer, Boston, MA. doi:0.1007/978-1-4615-3792$2 \_29$

Milgrom, P., Kleinknecht, R. A., Elliott, J., Hsing, L. H., \& Choo-Soo, T. (1990). A crosscultural cross validation of the Dental Fear Survey in South East Asia. Behaviour Research and Therapy, 28(3), 227-233. doi:10.1016/0005-7967(90)90005-4

Milgrom, P., Mancl, L., King, B., \& Weinstein, P. (1995). Origins of childhood dental fear. Behaviour Research and Therapy, 33(3), 313-319. doi:10.1016/00057967(94)00042-I

Muris, P., Steerneman, P., Merckelbach, H., \& Meesters, C. (1996). The role of parental fearfulness and modeling in children's fear. Behaviour Research and Therapy, 34(3), 265-268. doi:10.1016/0005-7967(95)00067-4

Ng, S. K., \& Leung, W. K. (2008). A community study on the relationship of dental anxiety with oral health status and oral health-related quality of life. Community Dentistry and Oral Epidemiology, 36(4), 347-356. doi:10.1111/j.1600-0528.2007.00412.x

Ollendick, T. H., \& King, N. J. (1991). Origins of childhood fears: An evaluation of Rachman's theory of fear acquisition. Behaviour Research and Therapy, 29(2), 117-123. doi:10.1016/0005-7967(91)90039-6 
Parpal, M., \& Maccoby, E.E. (1985). Maternal responsiveness and subsequent child compliance. Child Development, 56, 1326-1334. doi:10.2307/1130247

Peterson, D. (2018). Oh no! I gotta go to the dentist. Herndon: Mascot Books.

Raadal, M., Milgrom, P., Weinstein, P., Mancl, L., \& Cauce, A. M. (1995). The prevalence of dental anxiety in children from low-income families and its relationship to personality traits. Journal of Dental Research, 74(8), 1439-1443.

doi:10.1177/00220345950740080201

Roberts, M. W., McMahon, R. J., Forehand, R., \& Humphreys, L. (1978). The effect of parental instruction-giving on child compliance. Behavior Therapy, 9(5), 793-798. doi:10.1016/S0005-7894(78)80009-4

Robinson, E. A., \& Eyberg, S. M. (1981). The dyadic parent-child interaction coding system: Standardization and validation. Journal of Consulting and Clinical Psychology, 49(2), 245. doi:10.1037/0022-006X.49.2.245

Rachman, S. (1977). The conditioning theory of fear-acquisition: A critical examination. Behaviour Research and Therapy, 15(5), 375-387. doi:10.1016/0005-7967(77)90041-9

Sachs-Ericsson, N., Verona, E., Joiner, T., \& Preacher, K. J. (2006). Parental verbal abuse and the mediating role of self-criticism in adult internalizing disorders. Journal of affective disorders, 93(1-3), 71-78. doi:10.1016/j.jad.2006.02.014

Schuller, A. A., Willumsen, T., \& Holst, D. (2003). Are there differences in oral health and oral health behavior between individuals with high and low dental fear?. Community Dentistry and Oral Epidemiology, 31(2), 116-121. doi:10.1034/j.1600-0528.2003.00026.x 
Shanley, J. R., \& Niec, L. N. (2011). The contribution of the Dyadic Parent-Child Interaction Coding System (DPICS) warm-up segments in assessing parent-child interactions. Child \& Family Behavior Therapy, 33(3), 248-263. doi:10.1080/07317107.2011.596009

Tan, T. X., Dedrick, R. F., \& Marfo, K. (2007). Factor structure and clinical implications of Child Behavior Checklist/15-5 ratings in a sample of girls adopted from China. Journal of Pediatric Psychology, 32(7), 807-818. doi:10.1093/jpepsy/jsm025

Ten Berge, M., Veerkamp, J. S., Hoogstraten, J., \& Prins, P. J. (2002). Childhood dental fear in the Netherlands: prevalence and normative data. Community Dentistry and Oral Epidemiology, 30(2), 101-107. doi:10.17245/jdapm.2016.16.3.199

Themessl-Huber, M., Freeman, R., Humphris, G., Macgillivray, S., \& Terzi, N. (2010).

Empirical evidence of the relationship between parental and child dental fear: a structured review and meta-analysis. International Journal of Paediatric Dentistry, 20(2), 83-101. doi:10.1111/j.1365-263X.2009.00998.x

United States Department of Health and Human Services. (2019). Annual Update of the HHS Poverty Guidelines. Retrieved November 21, 2019.

Vermaire, J. H., De Jongh, A., \& Aartman, I. H. (2008). Dental anxiety and quality of life: the effect of dental treatment. Community Dentistry and Oral Epidemiology, 36(5), 409-416. doi:10.1111/j.1600-0528.2007.00416.x

Walker, H. M., \& Walker, J. E. (1991). Coping with noncompliance in the classroom: A positive approach for teachers. Austin: Pro Ed.

Wang, M. T., \& Kenny, S. (2014). Longitudinal links between fathers' and mothers' harsh verbal discipline and adolescents' conduct problems and depressive symptoms. Child Development, 85(3), 908-923. doi:10.1111/cdev.12143 
Weinstein, P. (1990). Breaking the worldwide cycle of pain, fear and avoidance: Uncovering risk factors and promoting prevention for children. Annals of Behavioral Medicine, 12, 141 147. doi:10.1093/abm/12.4.141

Wogelius, P., Poulsen, S., \& Toft Sørensen, H. (2003). Prevalence of dental anxiety and behavior management problems among six to eight years old Danish children. Acta Odontologica Scandinavica, 61(3), 178-183. doi:10.1080/00016350310003468

Wolpe, J. (1969). The Practice of Behavior Therapy. New York: Pergamon Press.

Wong, D. L., \& Baker, C. M. (1988). Pain in children: comparison of assessment scales. Pediatr Nurs, 14(1), 9-17.

Vissing, Y. M., Straus, M. A., Gelles, R. J., \& Harrop, J. W. (1991). Verbal aggression by parents and psychosocial problems of children. Child Abuse \& Neglect, 15(3), 223-238. doi:0.1016/0145-2134(91)90067-N

Zhou, Y., Cameron, E., Forbes, G., \& Humphris, G. (2011). Systematic review of the effect of dental staff behaviour on child dental patient anxiety and behaviour. Patient Education and Counseling. doi:10.1016/j.pec.2010.08.002 


\section{Table 1.}

Definitions and Examples of DPICS-IV Codes

\begin{tabular}{|c|c|}
\hline Code & Definition \\
\hline Neutral talk (TA) & $\begin{array}{l}\text { "...information about other people, objects, events, or activities, or } \\
\text { simply acknowledge current activity, but do not direct, describe, or } \\
\text { evaluate the child's current or immediately completed behavior" } \\
\text { (Eyberg, Chase, Fernandez, \& Nelson, } 2014 \text {, p. } 55 \text { ). }\end{array}$ \\
\hline Behavior Description (BA) & $\begin{array}{l}\text { "... a non-evaluative, declarative sentence or phrase in which the subject } \\
\text { is the child and the verb describes the child's ongoing or immediately } \\
\text { completed ( }<5 \text { sec.) observable verbal or nonverbal behavior" (Eyberg, } \\
\text { Chase, Fernandez, \& Nelson, } 2014 \text {, p. } 51) \text {. }\end{array}$ \\
\hline Reflection (RF) & $\begin{array}{l}\text { "...a declarative phrase or statement that has the same meaning as a } \\
\text { child verbalization" (Eyberg, Chase, Fernandez, \& Nelson, 2014, p. 45). }\end{array}$ \\
\hline Question (QU) & $\begin{array}{l}\text { "... a verbal inquiry from parent to child that is distinguishable from a } \\
\text { declarative statement by having a rising inflection at the end or by } \\
\text { having the sentence structure of a question" (Eyberg, Chase, Fernandez, } \\
\text { \& Nelson, 2014, p. 43). }\end{array}$ \\
\hline Unlabeled praise (UP) & $\begin{array}{l}\text { "... a positive evaluation of the child, an attribute of the child, or a } \\
\text { nonspecific activity, behavior, or product of the child" (Eyberg, Chase, } \\
\text { Fernandez, \& Nelson, } 2014 \text {, p. } 41 \text { ). }\end{array}$ \\
\hline Labeled praise (LP) & $\begin{array}{l}\text { "... a positive evaluation of a specific attribute, product, or behavior of } \\
\text { the child" (Eyberg, Chase, Fernandez, \& Nelson, 2014, p. 37). }\end{array}$ \\
\hline Direct command (DC) & "... a declarative statement that contains an order or direction for a vocal \\
\hline
\end{tabular}


performed and indicates that the child is to perform this behavior" (Eyberg, Chase, Fernandez, \& Nelson, 2014, p. 27).

Indirect command (IC) “...a suggestion for avocal, motor, mental, or internal, unobservable action to be performed that is stated either in question form or such that it is unclear if the child must complete the request (Eyberg, Chase, Fernandez, \& Nelson, 2014, p. 29).

Negative talk (NTA) “...verbal expression of disapproval of the child or the child's attributes, activities, products, or choice" (Eyberg, Chase, Fernandez, \& Nelson, 2014, p. 19).

Child compliance (CO) “...the child performs, begins, to perform, or attempts to perform a behavior requested by the parent within the 5 -second interval following a command" (Eyberg, Chase, Fernandez, \& Nelson, 2014, p. 71).

Child noncompliance (NC) “... the child does not perform, does not attempt to perform, or stops attempting to perform the requested behavior within the 5-second interval following the command" (Eyberg, Chase, Fernandez, \& Nelson, 2014, p. 73).

Child no opportunity for "... the child is not given an adequate change to comply with a compliance (NOC) command or if it is not possible to determine if the child has complied" (Eyberg, Chase, Fernandez, \& Nelson, 2014, p. 75).

Child no opportunity for The child was not given an adequate chance to comply with a command compliance from other (NOCO) interfering with compliance 
Table 2

Caregiver Sample Characteristics

\begin{tabular}{|c|c|c|c|c|}
\hline Characteristic & $n$ & $\%$ & $M$ & $S D$ \\
\hline Caregiver Age & 131 & & 33.3 & 7.71 \\
\hline \multicolumn{5}{|l|}{ Caregiver Gender } \\
\hline Female & 123 & $88.5 \%$ & & \\
\hline Male & 16 & $11.5 \%$ & & \\
\hline \multicolumn{5}{|l|}{ Caregiver Race } \\
\hline African American & 26 & $18.7 \%$ & & \\
\hline American Indian/Alaska Native & 3 & $2.2 \%$ & & \\
\hline Asian American & 11 & $7.9 \%$ & & \\
\hline White & 99 & $71.2 \%$ & & \\
\hline Other & 4 & $2.9 \%$ & & \\
\hline \multicolumn{5}{|l|}{ Caregiver Ethnicity } \\
\hline Hispanic/Latino & 4 & $2.9 \%$ & & \\
\hline \multicolumn{5}{|l|}{ Caregiver Relationship } \\
\hline Mother & 116 & $83.5 \%$ & & \\
\hline Father & 14 & $10.1 \%$ & & \\
\hline Other & 9 & $6.5 \%$ & & \\
\hline \multicolumn{5}{|l|}{ Marital Status } \\
\hline Married & 95 & $67.9 \%$ & & \\
\hline Living with Partner & 14 & $10.0 \%$ & & \\
\hline Separated & 1 & $0.7 \%$ & & \\
\hline Divorced & 4 & $2.9 \%$ & & \\
\hline Never Married & 21 & $15.0 \%$ & & \\
\hline Other & 5 & $3.6 \%$ & & \\
\hline \multicolumn{5}{|l|}{ Marital Status } \\
\hline$<9$ th Grade & 3 & $2.1 \%$ & & \\
\hline Some High School & 3 & $2.1 \%$ & & \\
\hline High School diploma or GED & 36 & $25.7 \%$ & & \\
\hline Some College & 40 & $28.6 \%$ & & \\
\hline Associate's Degree & 10 & $7.1 \%$ & & \\
\hline Bachelor's Degree & 12 & $8.6 \%$ & & \\
\hline Some Graduate School & 4 & $2.9 \%$ & & \\
\hline Master's Degree & 19 & $13.6 \%$ & & \\
\hline Doctoral Degree & 13 & $9.3 \%$ & & \\
\hline \multicolumn{5}{|l|}{ Yearly Income } \\
\hline$\$ 0 /$ year & 5 & $3.7 \%$ & & \\
\hline$\$ 1-999 /$ year & 6 & $4.5 \%$ & & \\
\hline$\$ 1,000-1,999 /$ year & 5 & $3.7 \%$ & & \\
\hline$\$ 2,000-3,999 /$ year & 4 & $3.0 \%$ & & \\
\hline$\$ 4,000-5,999 /$ year & 4 & $3.0 \%$ & & \\
\hline$\$ 6,000-7,999 /$ year & 1 & $0.7 \%$ & & \\
\hline$\$ 8,000-9,999 /$ year & 1 & $0.7 \%$ & & \\
\hline
\end{tabular}


$\$ 10,000-14,999 /$ year

$\$ 15,000-24,999 /$ year

$\$ 25,000-34,999 /$ year

$\$ 35,000-49,999 /$ year

$\$ 50,000-74,999 /$ year

$\$ 75,000-99,999 /$ year

$\$ 100,000-149,999 /$ year

$\$ 150,000-199,999 /$ year

$\$ 200,000$ or more/year

Employment

Working Full-time

Working Part-time

Not Employed but Seeking Employment

Not Employed but Not Seeking Employment

Retired

Other

Household Size

2

3

4

5

6

7

8

$\begin{array}{cc}3 & 2.2 \% \\ 19 & 14.2 \% \\ 11 & 8.2 \% \\ 20 & 14.9 \% \\ 22 & 16.4 \% \\ 10 & 7.5 \% \\ 8 & 6.0 \% \\ 2 & 1.5 \% \\ 13 & 9.7 \%\end{array}$

$52 \quad 37.4 \%$

$31 \quad 22.3 \%$

$19 \quad 13.7 \%$

$25 \quad 18.0 \%$

$3 \quad 2.2 \%$

$9 \quad 6.5 \%$

$13 \quad 9.3 \%$

$35 \quad 25.0 \%$

$44 \quad 31.4 \%$

$26 \quad 18.6 \%$

$9 \quad 6.4 \%$

$6 \quad 4.3 \%$

$7 \quad 5.0 \%$ 
Table 3

Child Sample Characteristics

\begin{tabular}{|c|c|c|c|c|}
\hline Characteristic & $n$ & $\%$ & $M$ & $S D$ \\
\hline Child Age Months & 139 & & 42.82 & 16.95 \\
\hline Child Age Years & 139 & & 3.05 & 1.47 \\
\hline 0 & 4 & $2.9 \%$ & & \\
\hline 1 & 20 & $14.4 \%$ & & \\
\hline 2 & 31 & $22.3 \%$ & & \\
\hline 3 & 25 & $18.0 \%$ & & \\
\hline 4 & 28 & $20.1 \%$ & & \\
\hline 5 & 31 & $22.3 \%$ & & \\
\hline \multicolumn{5}{|l|}{ Child Sex } \\
\hline Female & 64 & $46.0 \%$ & & \\
\hline Male & 75 & $54.0 \%$ & & \\
\hline \multicolumn{5}{|l|}{ Child Race } \\
\hline African American & 32 & $23.0 \%$ & & \\
\hline American Indian/Alaska Native & 2 & $1.4 \%$ & & \\
\hline Asian American & 10 & $7.2 \%$ & & \\
\hline White & 97 & $69.8 \%$ & & \\
\hline Other & 6 & $4.3 \%$ & & \\
\hline \multicolumn{5}{|l|}{ Child Ethnicity } \\
\hline Hispanic/Latino & 6 & $4.4 \%$ & & \\
\hline \multicolumn{5}{|l|}{ Autism Spectrum Disorder } \\
\hline Yes & 3 & $2.1 \%$ & & \\
\hline No & 137 & $97.9 \%$ & & \\
\hline \multicolumn{5}{|l|}{ Attention Deficit Hyperactivity Disorder } \\
\hline Yes & 2 & $1.5 \%$ & & \\
\hline No & 135 & $98.5 \%$ & & \\
\hline \multicolumn{5}{|l|}{ Intellectual Disability/Developmental Delay } \\
\hline Yes & 7 & $5 \%$ & & \\
\hline No & 132 & $95.0 \%$ & & \\
\hline \multicolumn{5}{|l|}{ Displays Separation Anxiety } \\
\hline Yes & 15 & $10.8 \%$ & & \\
\hline No & 124 & $89.2 \%$ & & \\
\hline \multicolumn{5}{|l|}{ Covered by Dental Insurance } \\
\hline Yes & 111 & $79.9 \%$ & & \\
\hline No & 28 & $20.1 \%$ & & \\
\hline \multicolumn{5}{|l|}{ If Covered, Dental Insurance Type } \\
\hline Private/Through Employer & 35 & $31.8 \%$ & & \\
\hline Medicaid & 48 & $43.6 \%$ & & \\
\hline Children's Health Insurance Program & 8 & $7.3 \%$ & & \\
\hline Other & 19 & $17.3 \%$ & & \\
\hline Number of Previous Dental Visits & & & 2.19 & 2.48 \\
\hline 0 & 34 & $25 \%$ & & \\
\hline 1 & 30 & $22.1 \%$ & & \\
\hline
\end{tabular}




\begin{tabular}{|c|c|c|c|c|}
\hline 2 & 24 & $17.6 \%$ & & \\
\hline 3 & 17 & $12.5 \%$ & & \\
\hline 4 & 17 & $12.5 \%$ & & \\
\hline 5 & 5 & $3.7 \%$ & & \\
\hline $6+$ & 9 & $6.6 \%$ & & \\
\hline \multicolumn{5}{|c|}{ Any Previous Dental Procedures Other Than Cleaning and Exam } \\
\hline Yes & 73 & $52.5 \%$ & & \\
\hline No & 66 & $47.5 \%$ & & \\
\hline \multicolumn{5}{|l|}{ Wong-Baker Faces Pain Scale } \\
\hline Pre-Appointment & & & 0.19 & 0.59 \\
\hline Post-Appointment & & & 0.08 & 0.30 \\
\hline \multicolumn{5}{|l|}{ Subjective Units of Distress Scale } \\
\hline Pre-Appointment & & & 12.71 & 19.37 \\
\hline Post-Appointment & & & 20.10 & 26.62 \\
\hline Child Behavior Check List T-Scores & 133 & & & \\
\hline Internalizing & & & 46.74 & 10.94 \\
\hline Externalizing & & & 45.06 & 10.40 \\
\hline Total & & & 45.47 & 11.76 \\
\hline
\end{tabular}




\section{Table 4}

Parameters from the Ordinal Regression of CFSS-DS Scores on Frankl Scores $(n=139)$

\begin{tabular}{lcccc} 
& \multicolumn{4}{c}{ Frankl Score } \\
CFSS-DS & 1 & 2 & 3 & 4 \\
\hline Cumulative logit & - & -4.614 & -3.163 & -0.595 \\
Cumulative odds & - & 0.01 & 0.04 & 0.55 \\
Cumulative proportion & 1.00 & 0.99 & 0.96 & 0.65 \\
Category probability & 0.01 & 0.03 & 0.31 & 0.65 \\
\hline
\end{tabular}

Notes. CFSS-DS = Dental Subscale of Children's Fear Survey.

Table 5

Logistic Regression Analysis for CFSS-DS associated with Binary Frankl $(n=139)$

\begin{tabular}{lccccc}
\hline \multicolumn{5}{c}{ Model $1^{\mathrm{a}}$} & \multicolumn{3}{c}{} \\
\hline Variable & $B$ & $S E B$ & OR & Lower CI & Upper CI \\
\hline Constant & -3.28 & 0.63 & $0.04^{*}$ & & \\
CFSS-DS & 0.07 & 0.02 & $1.07^{*}$ & 1.04 & 1.11 \\
\hline
\end{tabular}

Notes. ${ }^{\mathrm{a}} R^{2}=0.19, p<.001 ; *{ }^{*} p<.001$; CFSS-DS = Dental Subscale of Children's Fear Survey.

\section{Table 6}

Logistic Regression Analysis for CFSS-DS Cut Scores on Binary Frankl Scores $(N=139)$

\begin{tabular}{lccccc}
\hline \multicolumn{7}{c}{ Model $1^{\mathrm{a}}$} \\
\hline Variable & $B$ & $S E B$ & OR & Lower CI & Upper CI \\
\hline Constant & -1.39 & 0.26 & $0.25^{* *}$ & & \\
CFSS-DS Cut Score & 1.30 & 0.40 & $3.65^{*}$ & 1.68 & 7.94 \\
\hline
\end{tabular}

Notes. ${ }^{\mathrm{a}} R^{2}=0.11, p=.001 ; * p=.001 ; * * p<.001$ CFSS-DS = Dental Subscale of Children's Fear Survey.

\section{Table 7}

Logistic Regression Analysis for DFS associated with Binary Frankl $(N=140)$

Model $1^{\mathrm{a}}$

\begin{tabular}{lcccccc}
\hline Variable & $B$ & $S E B$ & OR & $p$ & Lower CI & Upper CI \\
\hline Constant & -0.49 & 0.45 & 0.27 & .270 & & \\
CFSS-DS & -0.01 & 0.01 & 0.99 & .304 & 0.97 & 1.01 \\
\hline
\end{tabular}

Notes. ${ }^{\mathrm{a}} R^{2}=0.01, p=.284 ; \mathrm{DFS}=$ Dental Fear Survey. 


\section{Table 8}

Correlation matrix of all participants across Frank, DFS, CFSS-DS, DPICS, CBCL, SUDS, and FACES

\begin{tabular}{|c|c|c|c|c|c|c|c|c|c|c|c|c|c|c|c|c|c|c|c|c|}
\hline & Frankl & $\begin{array}{l}\text { CFSS } \\
\text {-DS }\end{array}$ & DFS & LP & UP & IC & $\mathrm{DC}$ & QU & NTA & $\mathrm{RF}$ & $\mathrm{BD}$ & TA & $\begin{array}{c}\text { CBCL } \\
\text { I }\end{array}$ & $\begin{array}{c}\text { CBCL } \\
\text { E }\end{array}$ & $\begin{array}{c}\text { CBCL } \\
\mathrm{T} \\
\end{array}$ & $\begin{array}{c}\text { Pre- } \\
\text { FACES } \\
\end{array}$ & $\begin{array}{c}\text { Pre- } \\
\text { SUDS } \\
\end{array}$ & $\begin{array}{c}\text { Post- } \\
\text { FACES } \\
\end{array}$ & $\begin{array}{c}\text { Post- } \\
\text { SUDS } \\
\end{array}$ & Age \\
\hline Frankl & -- & & & & & & & & & & & & & & & & & & & \\
\hline CFSS-DS & $-.39 * *$ & -- & & & & & & & & & & & & & & & & & & \\
\hline DFS & .10 & .09 & -- & & & & & & & & & & & & & & & & & \\
\hline LP & .18 & -.06 & $.23^{*}$ & -- & & & & & & & & & & & & & & & & \\
\hline UP & .16 & .00 & -.10 & -.05 & -- & & & & & & & & & & & & & & & \\
\hline IC & -.16 & .01 & .07 & -.11 & -.13 & -- & & & & & & & & & & & & & & \\
\hline $\mathrm{DC}$ & -.04 & -.01 & .05 & -.02 & $-.24 *$ & .01 & -- & & & & & & & & & & & & & \\
\hline QU & .06 & .03 & -.16 & .05 & -.08 & .02 & $-.30 * *$ & -- & & & & & & & & & & & & \\
\hline NTA & -.15 & -.02 & -.03 & .00 & $-.30^{* *}$ & $.21^{*}$ & .03 & $-.20^{*}$ & -- & & & & & & & & & & & \\
\hline RF & -.16 & .08 & .00 & .03 & -.09 & .06 & .01 & .12 & -.14 & -- & & & & & & & & & & \\
\hline $\mathrm{BD}$ & .01 & -.02 & -.04 & .00 & $.27 * *$ & -.01 & .00 & -.14 & -.13 & $.46^{* *}$ & -- & & & & & & & & & \\
\hline TA & -.03 & .03 & .17 & .03 & -.13 & $-.30 * *$ & $-.43 * *$ & $-.19 *$ & $-.20 *$ & $-.21^{*}$ & $-.22 *$ & -- & & & & & & & & \\
\hline CBCL I & -.12 & $.29 * *$ & .09 & -.11 & -.13 & -.08 & .03 & -.17 & .13 & .03 & .11 & .05 & -- & & & & & & & \\
\hline CBCL E & -.07 & .03 & .13 & -.01 & -.08 & -.07 & .07 & -.17 & $.23 *$ & -.04 & .16 & -.03 & $.63 * *$ & -- & & & & & & \\
\hline CBCL T & -.09 & .13 & .13 & -.02 & -.08 & -.07 & -.03 & -.18 & .16 & -.05 & .15 & .09 & $.79 * *$ & $.83^{* *}$ & -- & & & & & \\
\hline Pre-FACES & .16 & .00 & -.02 & -.04 & .00 & .06 & .09 & .04 & -.01 & -.08 & -.05 & -.07 & .13 & -.01 & .00 & -- & & & & \\
\hline Pre-SUDS & -.02 & $.26^{* *}$ & .09 & .01 & .12 & .19 & -.09 & .06 & .04 & -.04 & .01 & -.07 & .08 & -.08 & -.01 & .09 & -- & & & \\
\hline Post-FACES & -.01 & .00 & -.09 & -.04 & .13 & -.10 & .04 & -.05 & .05 & -.06 & $.22^{*}$ & -.08 & $.21^{*}$ & $.23 *$ & $.20^{*}$ & .15 & .63 & -- & & \\
\hline Post-SUDS & $-.53^{* *}$ & $.48^{* *}$ & -.01 & -.14 & -.03 & .07 & -.05 & -.05 & .12 & .01 & .05 & .03 & .16 & .06 & .13 & -.05 & $.28^{* *}$ & .09 & -- & \\
\hline Age & $.26^{* *}$ & -.08 & .09 & .08 & .02 & -.16 & -.15 & .01 & -.04 & -.12 & -.11 & .17 & .10 & -.07 & -.07 & $.17^{*}$ & .10 & .07 & -.11 & -- \\
\hline
\end{tabular}

Note. Correlations for all participants $(N=140)$ in the sample are presented below the diagonal. For nearly all scales, higher scores are indicative of more extreme responding in the direction of the construct assessed, except on the Frankl. Higher scores on the Frankl are 
indicative of more positive child behavior during dental appointments. Frankl = Frankl behavioral rating scale; CFSS-DS $=$ Dental Subscale of Children's Fear Survey total score; DFS = Dental Fear Survey total score; LP = Ratio of total labeled praises over total number of complete thoughts; UP = Ratio of total unlabeled praises over total number of complete thoughts; IC $=$ Ratio of total indirect commands over total number of complete thoughts; DC $=$ Ratio of total direct commands over total number of complete thoughts; QU = Ratio of total questions over total number of complete thoughts; NTA = Ratio of total negative talks over total number of complete thoughts; RF = Ratio of total reflections over total number of complete thoughts; BD = Ratio of total behavior descriptions over total number of complete thoughts; TA = Ratio of total neutral talks over total number of complete thoughts; CBCL $\mathrm{I}=\mathrm{CBCL}$ Internalizing T-score; CBCL E $=$ CBCL Externalizing T-score; CBCL T $=$ CBCL Total T-score; Pre-FACES $=$ preappointment FACES score; Pre-SUDS = pre-appointment SUDS score; Post-FACES = post-appointment FACES score; Post-SUDS = post-appointment SUDS; Age = child age in months.

$* p<.05, * * p<.01$. 
Table 9

Caregiver-child DPICS-IV sample characteristics $(N=111)$

\begin{tabular}{|c|c|c|c|c|}
\hline & $M$ & $S D$ & Minimum & Maximum \\
\hline LP & .21 & .76 & 0 & 7 \\
\hline UP & 4.68 & 5.58 & 0 & 35 \\
\hline $\mathrm{IC}$ & 4.94 & 6.89 & 0 & 32 \\
\hline $\mathrm{DC}$ & 17.18 & 20.17 & 0 & 90 \\
\hline QU & 16.01 & 23.89 & 0 & 162 \\
\hline NTA & 4.36 & 7.33 & 0 & 46 \\
\hline $\mathrm{RF}$ & .74 & 1.72 & 0 & 13 \\
\hline $\mathrm{BD}$ & .42 & .98 & 0 & 5 \\
\hline TA & 33.07 & 39.22 & 0 & 259 \\
\hline Complete Thoughts & 81.63 & 90.00 & 0 & 569 \\
\hline LP Ratio $^{c}$ & .00 & .00 & .00 & .04 \\
\hline UP Ratio $^{\mathrm{c}}$ & .07 & .09 & .00 & .47 \\
\hline IC Ratio ${ }^{c}$ & .05 & .05 & .00 & .25 \\
\hline DC Ratio $^{c}$ & .21 & .13 & .00 & .65 \\
\hline QU Ratio $^{c}$ & .18 & .11 & .00 & .48 \\
\hline NTA Ratio ${ }^{c}$ & .06 & .08 & .00 & .38 \\
\hline RF Ratio $^{c}$ & .01 & .03 & .00 & .23 \\
\hline
\end{tabular}



BD Ratio ${ }^{c}$
.01
.02
.00
.20
TA Ratio ${ }^{c}$
.40
.15
.00
.85

Note. Sample characteristics for all participants $(N=111)$ are presented. $\mathrm{LP}=$ labeled praise; $\mathrm{UP}=$ unlabeled praise; IC $=$ indirect commands; $\mathrm{DC}=$ direct commands; $\mathrm{QU}=$ question; $\mathrm{NTA}=$ negative talk; $\mathrm{RF}=$ reflection; $\mathrm{BD}=$ behavior description; $\mathrm{TA}=$ neutral talk.

${ }^{c}$ Ratio of specified DPICS code over total number of complete thoughts 


\section{Appendix A: Demographic Information}

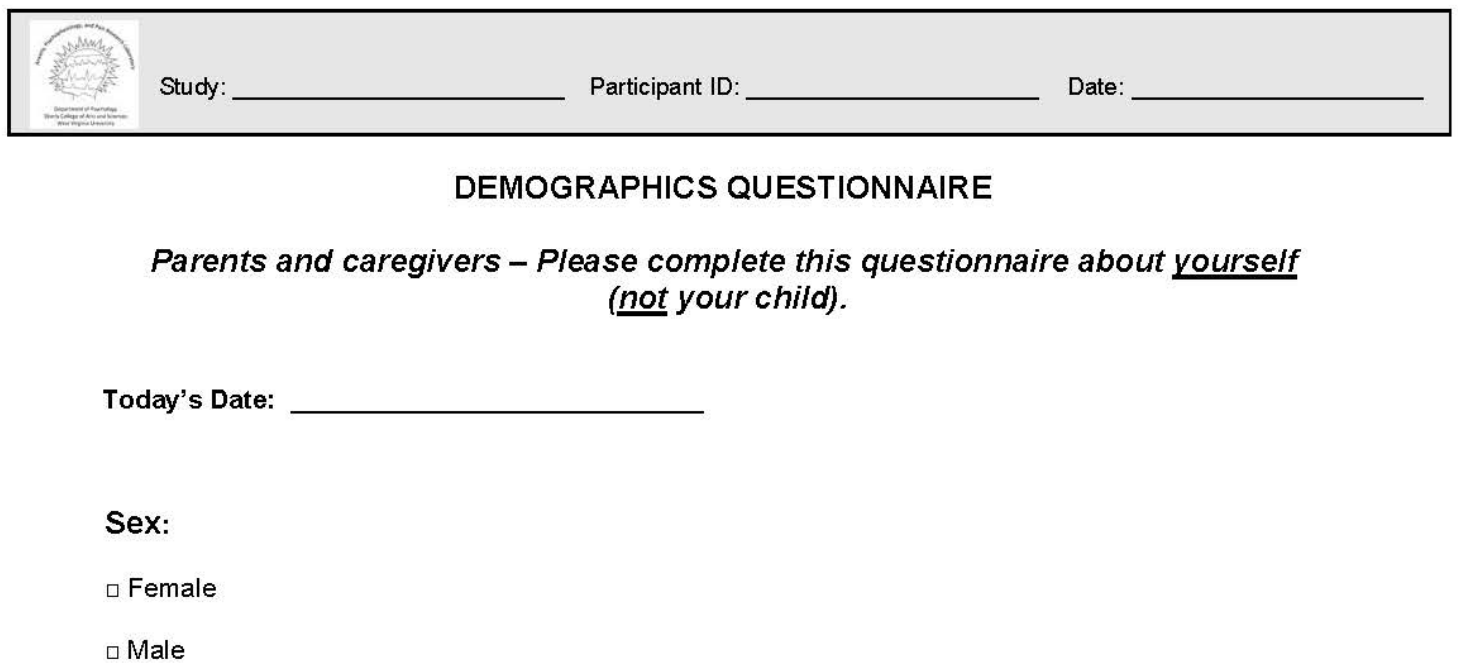

Age:

Race:

$\square$ White / Caucasian

$\square$ Black / African American

$\square$ Asian American

$\checkmark$ American Indian or Alaska Native

$\square$ Other (please describe) -

Are you Hispanic/Latino?

$\square$ Yes

$\square$ No

What is your relationship to the child who is participating in this study? 


\section{DEMOGRAPHICS - PARENT/CAREGIVER - PAGE 2}

What is your current marital status?

$\square$ Married
$\square \quad$ Living with Partner
$\square \quad$ Separated
$\square \quad$ Divorced
$\square \quad$ Never Married
$\square \quad$ Other:

What is the highest level of education you have received?

$\begin{array}{lll}\square & \text { Less than } 9^{\text {th }} \text { Grade } & \text { Bachelor's degree } \\ \square & \text { Some high school } & \text { Some graduate school } \\ \square & \text { High school diploma or GED } & \text { Master's degree } \\ \square & \text { Some college } & \text { Doctoral degree } \\ \square & \end{array}$

What is your current employment status?

\begin{tabular}{|c|c|}
\hline Working full-time & Not employed but seeking employment \\
\hline Working part-time & Not employed but not seeking employment \\
\hline Retired & Other (please describe): \\
\hline
\end{tabular}

What is your current occupation (or past if unemployed)?

How many people live in your

home? 


\section{DEMOGRAPHICS - PARENT/CAREGIVER - PAGE 3}

What is your current total household income? (Please check one)

\begin{tabular}{|c|c|}
\hline 0 & $15,000-24,999$ \\
\hline $1-999$ & $25,000-34,999$ \\
\hline $1,000-1,999$ & $35,000-49,999$ \\
\hline $2,000-3,999$ & $50,000-74,999$ \\
\hline $4,000-5,999$ & $75,000-99,999$ \\
\hline $6,000-7,999$ & $100,000-149,999$ \\
\hline $8,000-9,999$ & $150,000-199,999$ \\
\hline $10,000-14,999$ & 200,000 or more \\
\hline
\end{tabular}


Study:

Participant ID:

Date:

\section{CHILD DEMOGRAPHICS QUESTIONNAIRE}

Parents and caregivers - Please complete this questionnaire about your child (not yourself).

Today's Date:

\section{Child's Sex:}

$\square$ Female

$\square$ Male

Child's Age:

Child's Date of Birth (month, day, year):

' 1

Child's Race:

$\square$ White / Caucasian

$\square$ Black / African American

$\square$ Asian American

$\square$ American Indian or Alaska Native

$\square$ Other (please describe) -

Is your child Hispanic/Latino?

$\square$ American Indian or Alaska Native $\square$ Other (please describe 


\section{DEMOGRAPHICS - PARENT/CAREGIVER - PAGE 2}

What medication(s) is your child currently taking?

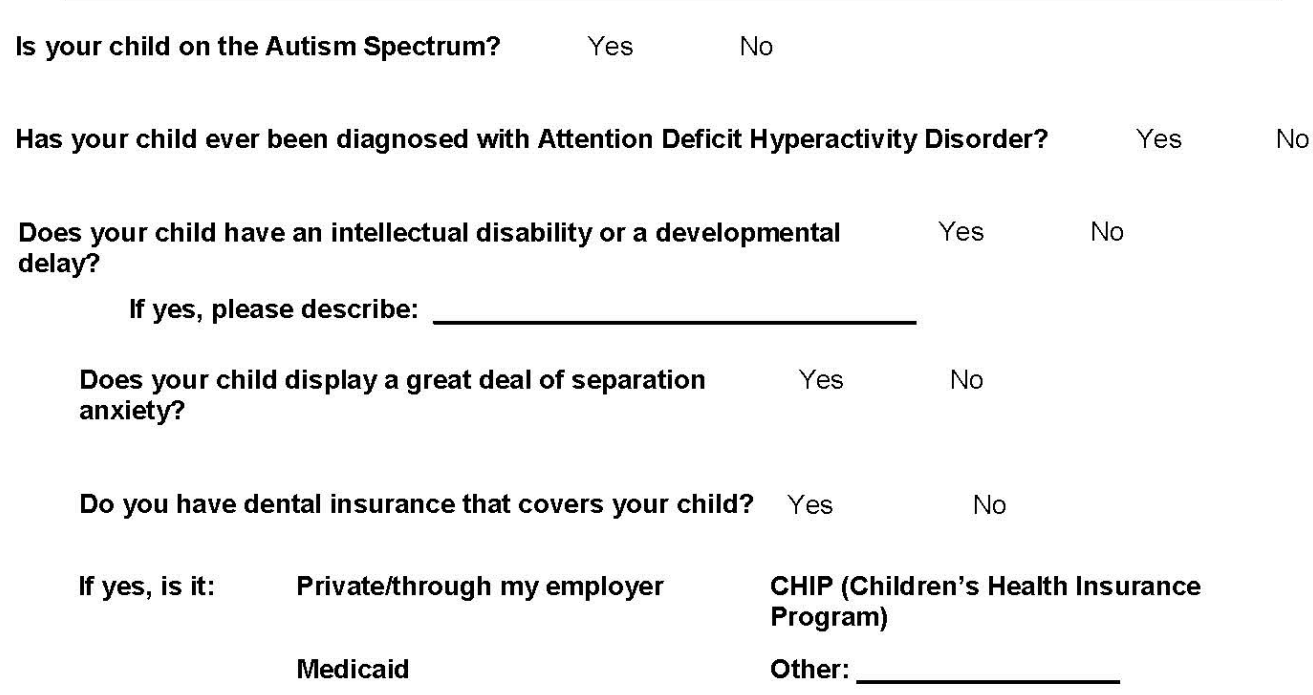

Has your child had any dental procedures other than a dental cleaning and exam? Yes

Approximately how many times has your child been to the dentist before today?

If yes, please describe: 


\section{Appendix B: Shared DPICS Frequently Encountered Rules}

* = research DPICS manual

** = clinical DPICS manual

\begin{tabular}{|c|c|c|c|}
\hline Codes & Example & Decision & Reference \\
\hline $\mathrm{AHH}$ & $\begin{array}{ll}\text { 1. } & \text { Open big, } \mathrm{AHH} \\
\text { 2. } & \text { AHHHHH } \\
\text { 3. } & \text { Say/Go AHHH } \\
\end{array}$ & $\begin{array}{ll}\text { 1. } & \text { DC, TA } \\
\text { 2. } & \text { TA } \\
\text { 3. } & \text { DC } \\
\end{array}$ & \\
\hline Information giving & $\begin{array}{l}\text { 1. We're going to try to take a couple } \\
\text { pictures first. } \\
\text { 2. Okay we're going to take two quick } \\
\text { pictures of your teeth sweetie okay? }\end{array}$ & $\begin{array}{l}\text { 1. TA (i.e., action done much later in time) } \\
\text { 2. QU (i.e., action done much later in time) }\end{array}$ & \\
\hline $\begin{array}{l}\text { Action currently } \\
\text { occurring }\end{array}$ & 1. We're just going to brush. & 1. IC (i.e., need child to participate) & \\
\hline There you go & $\begin{array}{l}\text { 1. There you go. (Handing something to } \\
\text { child) } \\
\text { 2. There you go! Good job! }\end{array}$ & $\begin{array}{ll}\text { 1. } & \text { TA } \\
\text { 2. } & \text { TA, UP }\end{array}$ & $93 *$ \\
\hline Alright & $\begin{array}{l}\text { 1. Alright ... } \\
\text { 2. Alright! (Gives high-five) } \\
\text { 3. All right! }\end{array}$ & $\begin{array}{ll}\text { 1. } & \mathrm{TA} \\
\text { 2. } & \mathrm{UP} \\
\text { 3. } & \mathrm{UP} \\
\end{array}$ & $\begin{array}{l}93 * \\
65 * \\
65 * \\
\end{array}$ \\
\hline Look & $\begin{array}{l}\text { 1. Look. } \\
\text { 2. Look at you! You are so cute. } \\
\text { 3. Look at those teeth. } \\
\text { 4. Look at those teeth! (smiles) } \\
\text { 5. Look at you opening so wide! }\end{array}$ & $\begin{array}{l}\text { 1. DC } \\
\text { 2. UP, UP (i.e., positive, evaluating child's behavior) } \\
\text { 3. DC (i.e., unclear if verbalization is directed to the } \\
\text { child, to the speaker, or to another person in the room. } \\
\text { Because it is unclear, you code the verbalization as if it } \\
\text { is directed to the child.) } \\
\text { 4. UP (i.e., positive, teeth = UP) } \\
\text { 5. LP (i.e., positive, specifying) }\end{array}$ & $\begin{array}{l}27 * * \\
41 * * \\
11 * * \\
38 * *\end{array}$ \\
\hline
\end{tabular}




\section{Appendix C: Shared DCIT-DPICS Decision Rules}

As you code, please place questions here in this table. We will use this to guide our weekly decision rules meeting. Once a question is answered it will be added to the decision rules table above. Please do not ever delete any questions in the table below, this will serve as a record that all coding questions were addressed. Additionally, you can use CTL + Find in this document to see if you have a

question that was previously answered.

\begin{tabular}{|c|c|c|}
\hline ID + Line \# & Questions & Status \\
\hline $\begin{array}{r}20030 \\
-447 \\
-484\end{array}$ & $\begin{array}{l}\text { D: I'm gonna have you put your hands on your belly button so it doesn't fly away? (taps child's } \\
\text { belly) } \\
\text { D: I'm gonna have you open real big. } \\
\text {-Are these coded as IC or TA? }\end{array}$ & $\begin{array}{l}\text { IC, "I'm gonna have you is not } \\
\text { clear enough to be coded as } \\
\text { DC." }\end{array}$ \\
\hline 220 & $\begin{array}{l}\text { DH: Mom and Dad, you should be so proud. } \\
\text {-command to parents? "You should..." } \\
\text { - praise to child? "Proud" }\end{array}$ & UP to child, DC to caregivers. \\
\hline \multirow[t]{3}{*}{258} & $\begin{array}{l}\text { DH: Mom and dad are so proud of you. (to child) } 258 \\
\text {-would this be a praise? }\end{array}$ & $\mathrm{UP}\left(2,56^{*}\right)$ \\
\hline & $\begin{array}{l}\text { DH: "Let's count all your teeth." } \\
\text {-indirect command? } \\
\text {-neutral talk? }\end{array}$ & IC \\
\hline & $\begin{array}{l}\text { Parent M: She said you're so big (talk about } \mathrm{DH}) \\
\text {-praise because saying he's a big boy? } \\
\text {-neutral talk? }\end{array}$ & $\mathrm{UP}\left(2,56^{*}\right)$ \\
\hline $\begin{array}{cc}20030 & \\
\bullet & 454-472\end{array}$ & $\begin{array}{l}\text { D: So yeah, I see a little stain on "I". but it doesn't look sticky. } \\
\text { D: And on "J" a little stain and same thing, it doesn't look sticky. So yeah she does pick up a } \\
\text { good bit of stain. } \\
\text { D: She's a groovy girl. She got some deep grooves and pits in her teeth. And I'm getting just a } \\
\text { slight stick on "T" occlusal. So one small cavity. } \\
\text { • How would we code these? Do the terms stain, grooves, and cavity carry } \\
\text { constitute NTA? (TA or NTA) }\end{array}$ & $\begin{array}{l}\text { TA, this is considered } \\
\text { information giving. It would } \\
\text { be NTA if the } \\
\text { provider said "You have } \\
\text { cavities because you never } \\
\text { brush your teeth". }\end{array}$ \\
\hline
\end{tabular}

